\title{
A developmental stretch-and-fill process that optimises dendritic wiring
}

Lothar Baltruschat ${ }^{\mathrm{a}, \mathrm{b}}$, Gaia Tavosanis ${ }^{\mathrm{a}, \mathrm{b}},{ }^{*}$ Hermann Cuntz ${ }^{\mathrm{a}, \mathrm{c}, \mathrm{d}}$

${ }^{a}$ Department of Systems and Computational Neurobiology, Max-Planck Institute of

Neurobiology, Martinsried, Germany

${ }^{b}$ Center for Neurodegenerative Diseases (DZNE), Bonn, Germany

${ }^{c}$ Ernst Strüngmann Institute (ESI) for Neuroscience in cooperation with the Max Planck

Society, Frankfurt-am-Main, 60528, Germany

${ }^{d}$ Frankfurt Institute for Advanced Studies, Frankfurt-am-Main, 60438, Germany

*cuntz@fias.uni-frankfurt.de

\section{Keywords}

Dendrite growth, Space filling, Minimum spanning tree, Model, da neurons, Fly 


\section{In brief}

We derive a detailed mathematical model that describes long-term time-lapse data of growing dendrites; it optimises total wiring and space-filling.

\section{Highlights}

- Dendrite growth iterations guarantee optimal wiring at each iteration.

- Optimal wiring guarantees optimal space filling.

- The growth rule from fly predicts dendrites of other cell types and species.

- Fly neurons stretch-and-fill target area with precise scaling relations.

- Phase transition of growth process between fly embryo and larval stages. 


\section{Abstract}

The way in which dendrites spread within neural tissue determines the resulting circuit connectivity and computation. However, a general theory describing the dynamics of this growth process does not exist. Here we obtain the first time-lapse reconstructions of neurons in living fly larvae over the entirety of their developmental stages. We show that these neurons expand in a remarkably regular stretching process that conserves their shape. Newly available space is filled optimally, a direct consequence of constraining the total amount of dendritic cable. We derive a mathematical model that predicts one time point from the previous and use this model to predict dendrite morphology of other cell types and species. In summary, we formulate a novel theory of dendrite growth based on detailed developmental experimental data that optimises wiring and space filling and serves as a basis to better understand aspects of coverage and connectivity for neural circuit formation.

\section{Introduction}

No one has to date proposed a theory of dendritic development that predicts the actual details of the biological growth process. Existing models describe the branching structures of mature dendrites using statistical growth rules (Koene et al., 2009), their spatial embedding (Luczak. 2006) or optimal wiring constraints (Cuntz et al., 2007, 2010). Only recently, time-lapse analysis has become more quantitative (Chalmers et al. 2016; Lee et al. 2013) enabling to link the developmental dendritic growth process with actual computational models. Understanding dendrite growth is essential to relate dendrite structure and the self-organisational process of neural circuit formation with respect to the set of all connections, i.e. the connectome (Denk et al., 2012). Also, only through simulations of dendritic development can the mature morphology be understood with respect to its underlying biology. We analyse in this work the maturation of the sensory dendritic arborisation (da) neurons of Drosophila larvae, a model system to study dendrite growth using genetics and molecular techniques (Jan and Jan, 2010). Among the da neurons, class IV ddaC (CIVda) cells tile (Grueber et al., 2002) and efficiently fill the available two-dimensional space (Shimono et al., 2010; Sugimura et al., 2007) via local interactions between neighbouring branches (Matthews et al., 2007; Soba et al., 2007). 


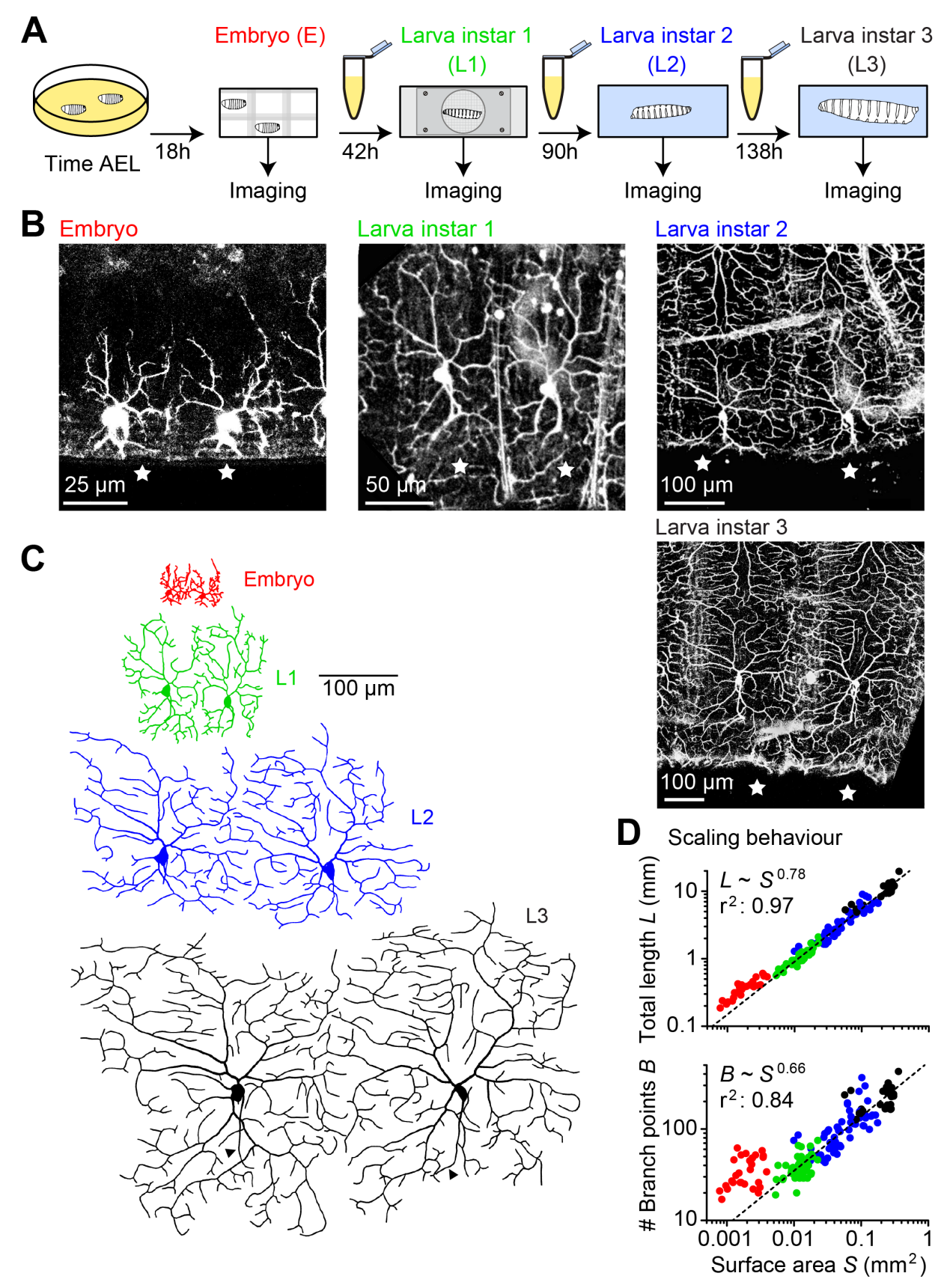

Fig 1. Long-term time-lapse imaging of CIVda neuron development.

A, Sketch illustrating the imaging procedure throughout Drosophila larva developmental stages: embryo (E), larval instar (L) 1,2 and 3. The larvae were kept in culture medium between the imaging steps. Times shown are AEL (after egg laying). B, Maximum intensity projections of image stacks from the same two neighbouring da dendrites (stars) for all four developmental stages. C, Digital reconstructions of the two neighbouring dendrites from $\mathbf{B}$ with small diameters clamped at $2 \mu \mathrm{m}$. Triangular markers in L3 show axons, which are ignored in the rest of the study. D, Scaling behaviour of total length $L$ and number of branch points $B$ against the total surface that the dendritic trees span $S$. Dashed lines show the best fit for data points L1-L3 with respective power and $r^{2}$ values. In all panels, the colours for the developmental stages are E (red), L1 (green), L2 (blue), L3 (black). 
Using live imaging, we obtained time-lapse reconstructions (Lee et al. 2013) of developing dendrites of the same CIVda neurons throughout larval development (E-L3), over the course of several days (Figure 1A). Remarkably, large parts of the dendritic architecture were conserved over all developmental stages while the overall shape was stretched, increasing the size homogeneously in all directions (Peng et al. 2015) (Figures 1B and C). Most importantly, individual dendritic branches from previous stages were easily identifiable and new branches grew in the space that became available through the extensive epidermal stretching. In the following, we dissect the stretch-and-fill process that underlies the development of CIVda dendrites, thereby formalising their maturation in a general theory of dendritic growth.

\section{Results}

\section{Scaling behaviour of CIVda neuron throughout larval development.}

In order to confine our model quantitatively, we first studied the scaling behaviour of dendritic morphological parameters during development, i.e. in which relation to one another their values increased (Cuntz et al., 2012; Iyer et al., 2013). The surface area $S$ covered by the dendritic trees increased by a factor of $62 \times$ between embryo (E) and third instar larva (L3) stages, consistent with previous observations (Parrish et al., 2009). After a phase of filling the dendrite's available spanning area in the embryo stage reflected in a different scaling behaviour (Parrish et al., 2009), $S$ scaled regularly with total dendrite cable length $L$ in the range of L1-L3 stages with a strict power relation of exponent $0.78\left(L \sim S^{0.78 ;} R^{2}=0.97\right)$. Branches appeared to fill up newly available space beyond a stretching process $\left(L \sim S^{1 / 2}\right.$, increasing the size without adding branches), however without conserving cable density $(L \sim S)$ throughout development (Figure 1D, top panel). Similarly, the number of branch points $B$ scaled with $S$ with an exponent of $0.66\left(B \sim S^{0.66} ; R^{2}=0.84\right)$ lingering between a pure stretching process with no new branches $\left(B \sim S^{0}\right.$, i.e. $B$ does not change with $\left.S\right)$ and a conservation of branch point density $(B \sim S$, a linear relation with an exponent of 1; Figure 1D, bottom panel). In line with a general growth process conserving dendritic features, all branching statistics that we studied scaled extensively with developmental stages (Figure 2A) but were essentially invariant of the developmental stage once the differences in overall sizes were normalised out (Figure 2B). 


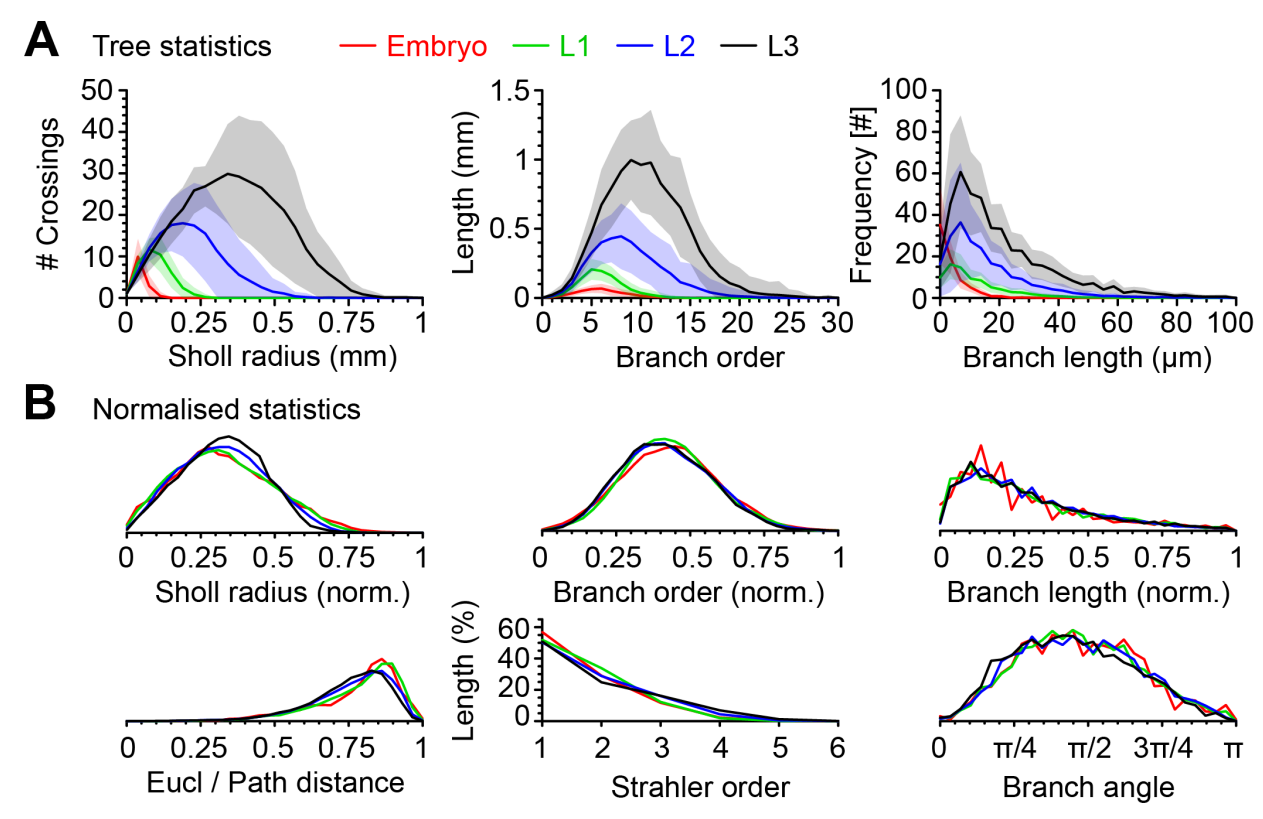

Fig 2. Branching statistics are similar throughout developmental scaling

A-B, Average branching statistics of reconstructions at the four developmental stages in absolute (A) and normalised (B) values. Panels in A indicate standard deviations in shaded areas. In all panels, the colours for the developmental stages are E (red), L1 (green), L2 (blue), L3 (black).

\section{Minimal wiring and optimal space filling.}

Since CIVda neurons possess space-filling dendrites we consider here an efficient coverage 59 of available surface area $S$ with short dendritic cable length $L$. Such an efficient coverage $\quad 60$ could be achieved by spreading out branches to regularly distributed target locations. As 61 a reference, we used targets on a closed hexagonal lattice arrangement that are well spread 62 (Figure 3A) (Hales, 2000). Tightly packed circles with radius $\theta$ around these targets are known 63 to cover $\frac{\pi}{2 \sqrt{3}} \approx 90.69 \%$ of total available $S$. This simple geometrical framework yields direct 64 relationships for all morphological variables of interest when connecting $N$ such targets to a 65 tree:

$$
\theta=\left(h^{-1 / 2} / 2\right) \cdot S^{1 / 2} \cdot N^{-1 / 2} \approx \frac{S}{(2 \cdot h \cdot L)} \quad L \approx h^{-1 / 2} \cdot S^{1 / 2} \cdot N^{1 / 2}
$$

where $h=\frac{\sqrt{3}}{2}$ (see Methods). In order to later compare these relations with random target $\quad 68$ distributions (Figure 3B) and real trees (Figure 3C), we also calculated their corresponding ${ }_{69}$ 

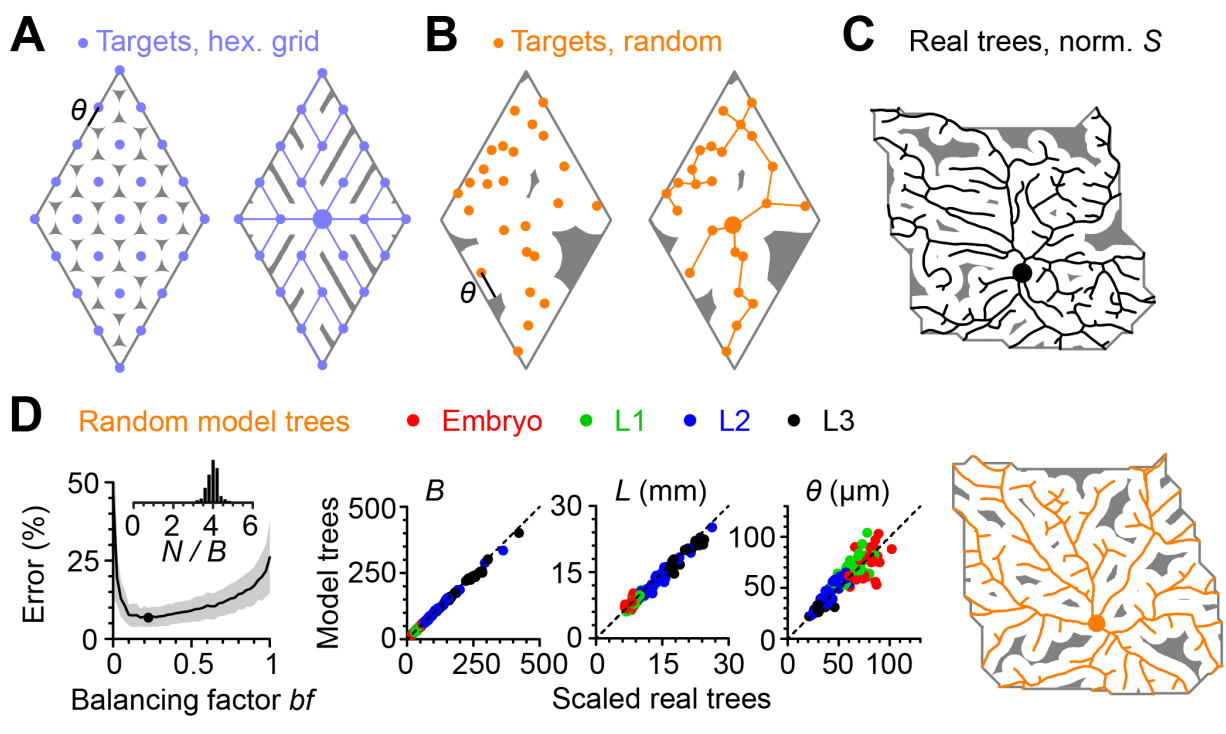

Tree statistics, synthetic trees
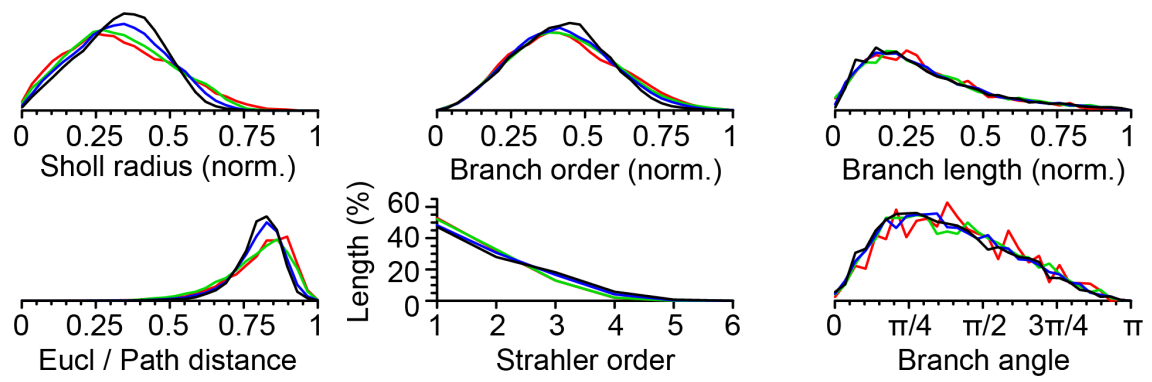

Fig 3. CIVda neuron minimal wiring and optimal space filling.

A, Targets (blue dots) distributed on a closed regular hexagonal grid optimise space coverage (left) and form a minimum spanning tree (blue straight lines) when connected to minimise total cable and path lengths toward the root (large blue dot, right). Grey shaded area indicates $10 \%(>\theta ; \theta$ shown as black line for one sample target) furthest away from targets (left) or from the tree (right). B, Similar arrangement as A but with random uniformly distributed targets (orange colours) as a comparison. C, Similar arrangement as A for real da dendrite normalised to the same $S$ as in A (targets are not shown since they are unknown). D, Model trees based on random homogeneously distributed targets in the dendrite spanning area (see Methods). Upper row (left to right): Model parameter $b f$ vs. error (comparing total length, branch order, compression and path length with corresponding real tree values; straight black line), optimal $b f(0.225$, black dot), standard deviation of the error (shaded area), and distribution of ratio values between numbers of targets and branch points (inset, $4.07 \pm 0.29$ ) for the optimal $b f$; Validation of number of branch points $B$, total cable length $L$ and space coverage $\theta$ between scaled real trees and model trees with dashed line indicating unity for comparison; sample random tree grown in the spanning area of the dendrite depicted in C. Lower part: similar panels as in Figure $2 \mathrm{~B}$ but for synthetic trees.

However, for a concrete comparison between real and synthetic trees, it was essential to 72 
estimate $N$ - the number of targets - an unknown measure in real trees. Fortunately, CIVda ${ }_{73}$ branching structures were well predicted by minimum spanning trees based on optimal 74 wiring constraints (Nanda et al., 2018), which were best matched in our case with a trade-off 75 parameter $b f=0.225$ between minimising total cable $L$ and path lengths $P L$ along the tree 76 from any target toward the root (Cost $=L+b f \cdot P L$; Figure 3D, upper left panel) (Cuntz et 77 al., 2007, 2008, 2010; Wen and Chklovskii, 2008). Such synthetic trees grown on a number 78 $N$ of randomly distributed targets within the spanning area of real dendrites to minimise 79 this effective cost matched all remaining branching statistics of their real counterparts after 80 simply matching the total number of branch points $B$ (Figure 3D). A tight ratio of $4.07 \pm 0.29 \quad 81$ between number of targets $N$ and number of branch points $B$ was observed in such synthetic $\quad 82$ dendrites (Figure 3D, left panel inset) (c.f. Cuntz et al., 2012) enabling us to estimate $N$ in real ${ }_{83}$ dendrites directly from $B(N=4.07 \times B)$.

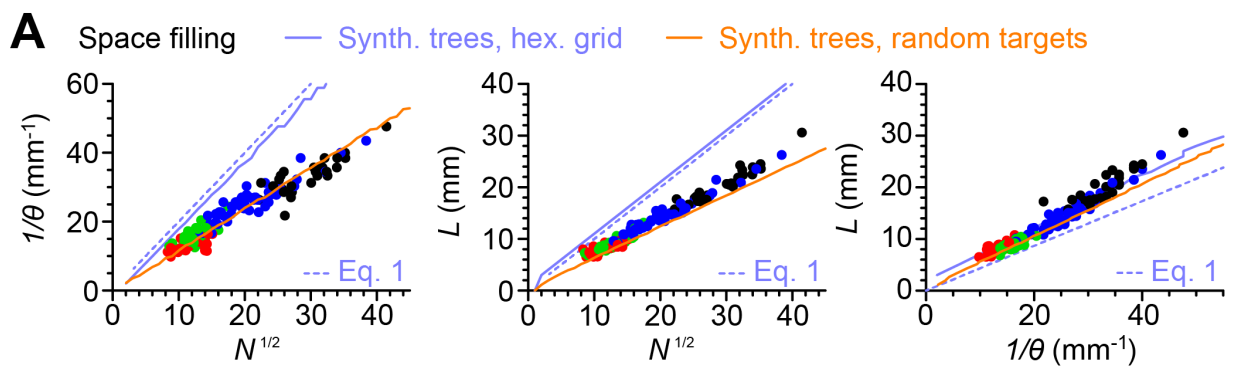

B Scaling model $N \sim S^{1 / 2}$

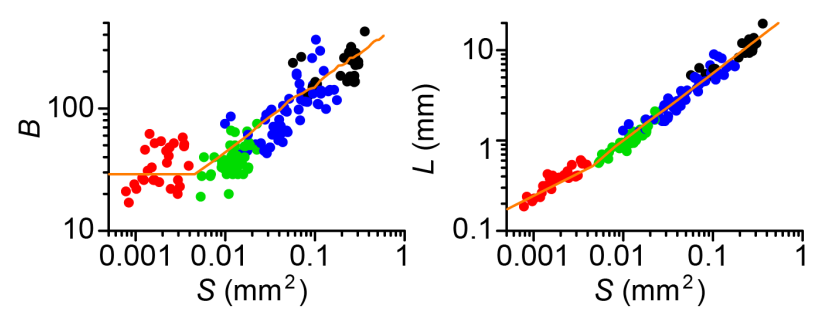

Fig 4. Modelling scaling relations in CIVda neuron development.

A, Comparison of the scaling behaviour of the variables in the space filling equations between real neurons (dots, same colours as in Figure 1D) and the two models shown in Figure $3 \mathbf{A}$ (Hexagonal arrangement, blue; dashed line Equation 1 for targets only, straight lines for connected trees) and Figure $3 \mathbf{B}$ (Random, orange lines). Number of branch points in real dendrites were converted to target number $N$ by the factor 4.07 obtained in Figure 3D. B, Scaling behaviour of the random model from Figure $3 \mathbf{B}$ (orange) assuming that target number $N$ grows with the side length of the surface area between L1-L3 compared with data from Figure $1 \mathrm{D}$.

Equipped with Equation 1 and after normalising $S$ in all cases we were able to isolate entirely 85 linear relationships between the square root of the number of target points $N^{1 / 2}, L$ and $\frac{1}{\theta}$, the $\quad 86$ 
inverse of $\theta$ quantifying the amount of space filling (Stepanyants et al., 2002). Interestingly, the ${ }_{87}^{87}$ corresponding scaling relationships indicated that real dendrites were shorter but less space 88 filling (smaller $\frac{1}{\theta}$ ) for one given $N$ than synthetic trees from well-spread targets on a hexagonal $\quad 89$ grid (Figure 44A, Equation 1). Real dendrites almost perfectly matched a configuration with 90 randomly distributed targets (compare orange lines and data in Figure $4 \mathrm{~A}$ ). However, when comparing $\frac{1}{\theta}$ and $L$ all configurations reached similar space filling for a given total length of dendrite (Figure 4A, Equation 1). Optimal wiring criteria seemed to, therefore, optimise space filling with respect to dendritic cable length regardless of target distributions, which seemed to be a general feature of minimum spanning trees. Optimally wired dendrites with uniformly distributed random targets were overall an excellent match for all measured CIVda neuron morphologies at all developmental stages and explained their specific space filling character. This could be qualitatively consistent with a random branching process of the Galton Watson type (Watson and Galton, 1875) that includes self-avoidance (Ganguly et al., 2016; Memelli et al., 2013). In fact, assuming that the number of targets $N$ is proportional to the side length (or square root) of the total surface area $S$ (Figure $4 \mathbf{B}$ ) such a model was also an excellent match for the precise scaling behaviour observed previously in Figure 1D. Thus, we can accurately model CIVda dendrites at each developmental stage. We therefore next addressed the developmental process leading to such optimally wired trees from one stage to the following.

\section{Dendritic developmental stretch-and-fill.}

In order to unravel the developmental growth process using the time-lapse data, we identified branch and termination points that were conserved in consecutive reconstructions using a newly developed semi-automated registration procedure (Figure 5A). The analysis unveiled a surprisingly linear and isometric stretching (Figure 5B) with a tight slope between the stretching vector and the distance of points from the dendrite root (Figure 5C). Interestingly, the overall origin of stretching did not lay precisely in the dendritic root location (Figure 5B) consistent with a possible impact of superficial epithelium extension on dendritic scaling during development (Jiang et al., 2014). 


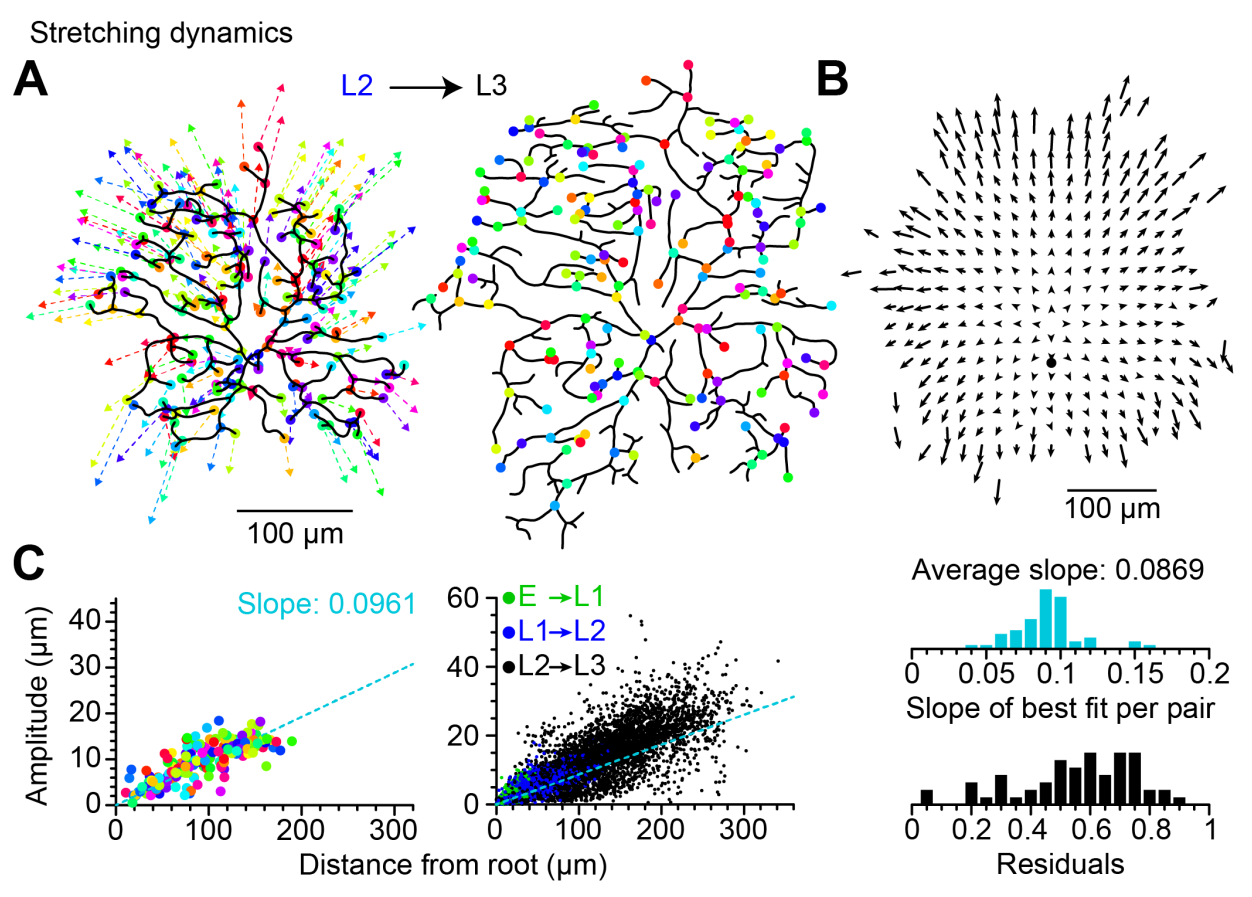

Fig 5. CIVda neuron developmental stretching.

A, Time-lapse data analysis: Branch and termination points (coloured dots) in time 1 (left, here L2) are registered to corresponding points in time 2 (right, here L3, same colour). The arrows on the left depict the movement of the respective topological points and illustrate the stretching of the entire structure between two acquisitions. B, Overall analysis for all pairs $(N=47)$. Arrows (every $25 \mu \mathrm{m})$ are averages only shown where data for at least 5 pairs were available. Dendrites were centred on their root (black dot). C, Analysis of stretching by comparing the arrow lengths (left, one dot per topological point with same colours as in A; right, topological points collected from all pairs with colours indicating larval instar at time 2 and their distance to the root. Linear fits (dashed cyan lines) determine the slope for all pairs (far right: histograms of slope values and residuals).

Our time-lapse registration method enabled us then to identify the new branches filling the empty space after the dendrite's linear stretching and the way they affected the scaling relationships (Figure 6A). Analogously to Figure 3 and 4 , we simulated the filling process by iteratively either connecting random targets within $S$ or targets that were selected to be maximally far away from the existing tree (Figure $6 \mathbf{B}$, orange and blue respectively; compare with pink new branches in the experimental dataset). Whereas random targets had efficiently 120 connected to realistic synthetic trees in one go, the iterative - developmental -- filling of real ${ }_{121}$ dendrites yielded slightly inferior space filling $\frac{1}{\theta}$ compared to the maximal filling model and $\quad 122$ fewer branch points $B$ than the random filling model. A mixed model, however, predicted ${ }_{123}$ both values appropriately (Figure $6 \mathbf{B}$, green) and enabled the growth process to remain on the ${ }^{124}$ realistic trajectories within the scaling behaviour plots (Figure $6 \mathbf{B}$, bottom panels; compare ${ }_{125}$ 
with Figure 6A). The results of the time-lapse analysis, therefore, put precise quantitative ${ }_{126}$ bounds to our growth model and indicated that a mixed model between maximal and random ${ }_{127}$ filling would best match the biological developmental iterations of dendrite growth.

Filling dynamics
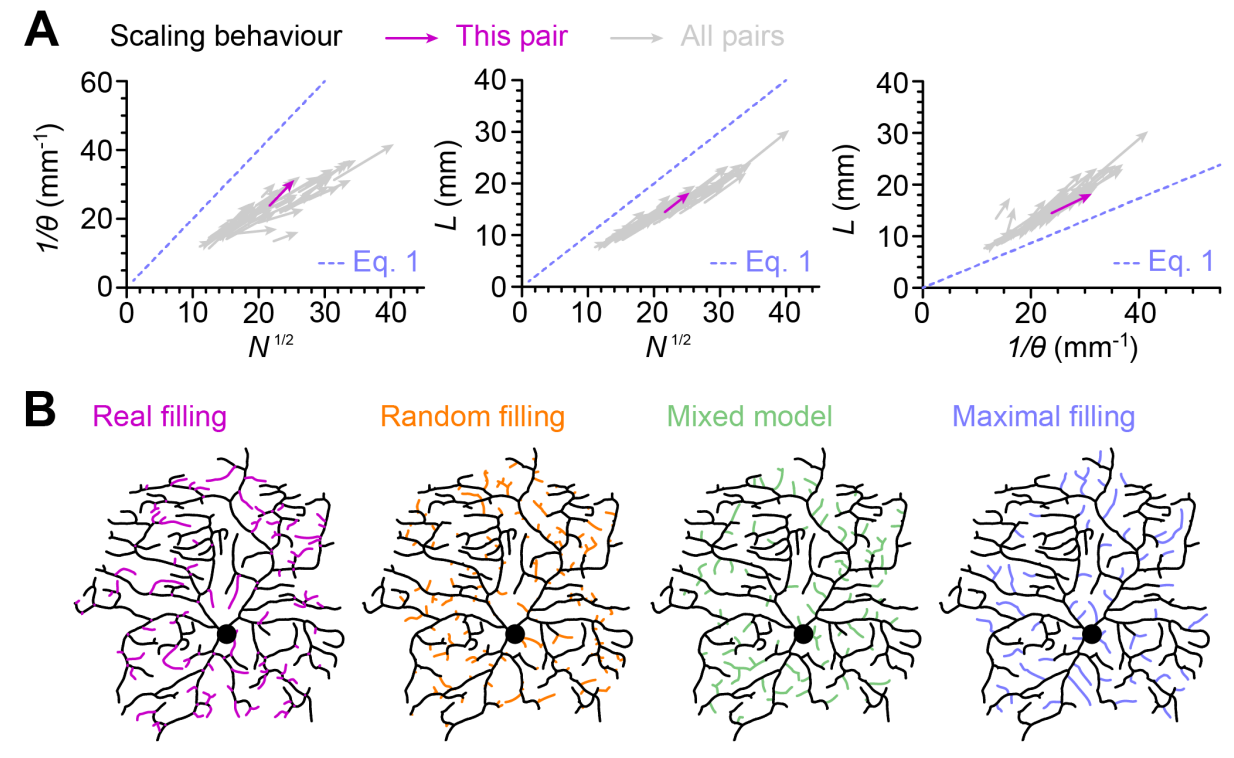

Maximal filling
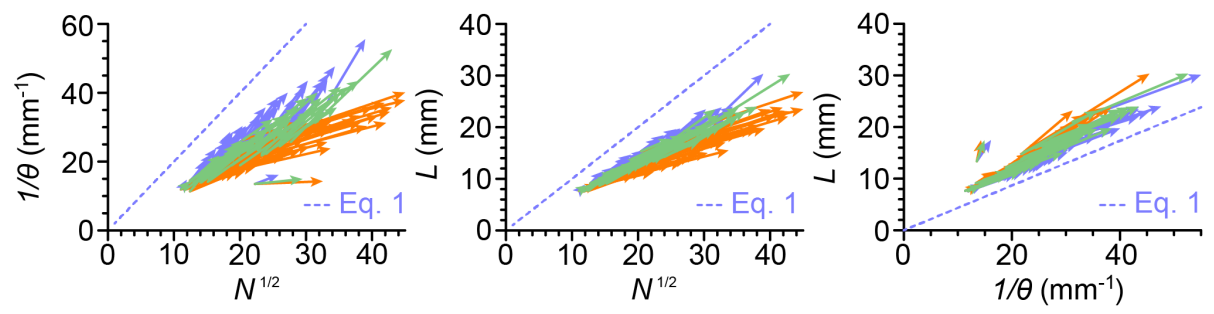

Fig 6. CIVda neuron developmental space-filling.

A, Scaling trajectories of variables defined in Figure 4 for all pairs in real cells (grey arrows) and the one example shown from Figure $5 \mathrm{~A}$ (pink arrow). B, Filling characterised by new branches in time 2 (real cell from Figure $5 \mathrm{~A}$, pink branches; black branches are conserved from time 1). Models filling randomly (orange), mixed (green), and maximally (blue) away from the existing dendrite (black tree with dots indicating the root). Panels show the trajectories obtained from model filling (orange dots - random, green dots - mixed model, blue dots - maximal, compare with A).

\section{Morphological model of dendrite development.}

Having formalised the growth process from one time point to the following we simulated the 130 developmental steps to grow entire synthetic dendrites de novo in the three different models (Figure 7). The mixed model reproduced the scaling behaviour that real dendrites underwent ${ }_{132}$ while optimising wiring and space filling throughout development. The resulting synthetic ${ }_{133}$ 
dendrites reproduced the shape of L1-L3 morphologies but failed to match the distinct aspect ${ }_{134}$ of embryo stage dendrites indicating once again that at the phase transition between E and L1 ${ }_{135}$ the mode of branching changed dramatically. Our synthetic developmental growth process ${ }_{136}$ was able to reproduce morphologies of other planar dendrites (cerebellar Purkinje cells and fly lobula plate tangential cells) and 3D dendrites (dentate granule cells, hippocampus pyramidal cells and cortical layer 5 pyramidal cells) as well as their space filling character (Figures $8 \mathrm{~A}$ and B). Our new iterative model represents a substantial improvement over our previous optimal wiring based models and will be useful at dissecting the developmental growth process leading to the mature dendritic morphology.

137

\section{Discussion}

In summary, we have shown how the iterations of dendrite growth lead to optimally wired morphologies throughout development, in other words how nature implements minimum spanning dendritic trees sequentially. We further have shown that optimally wired minimum spanning trees necessarily lead to optimal space filling regardless whether targets are distributed randomly or spread out maximally, meaning that minimising dendritic cable length guarantees optimal space filling in all cases. Our synthetic growth algorithm completely describes CIVda neurons showing that the dendrites of these cells are optimally built to constrain wire and explaining the scaling behaviour that most likely conserves connectivity (Gerhard et al., 2017) and function (Cuntz et al., 2013). The scaling behaviour exhibits a phase transition between embryo and L1-L3 (Parrish et al. 2009) that is similar to observations that have been made in C. elegans (Nicosia et al., 2013). Our models open up the possibility in the future to associate mutant phenotypes or elements of structural plasticity to parameter alterations in our model to better understand the underlying mechanisms of dendrite growth (Tavosanis, 2012; Yalgin et al., 2015). In our model, new targets that are chosen to be far from the existing tree are connected to a close node on the existing tree while also considering short paths in the dendrite. Elucidating the precise dynamics of elongation and retraction due to repulsion from other branches and molecules that establish the dendritic territory (Hattori et al., 2009: Matthews et al., 2007; Parrish et al., 2007) will require time-lapse analysis with much higher temporal resolution (Chalmers et al. 2016: He and Cline, 2011). However, with the current model in hand, quantitative predictions for such studies are given. Ultimately, pur model will link neurite outgrowth and space filling with circuit formation (Schröter et 
bioRxiv preprint doi: https://doi.org/10.1101/2020.07.07.191064; this version posted July 7, 2020. The copyright holder for this preprint (which

was not certified by peer review) is the author/funder, who has granted bioRxiv a license to display the preprint in perpetuity. It is made available under ACC-BY-NC-ND 4.0 International license.

Dendrite growth rule

Baltruschat, Tavosanis \& Cuntz

al. 2017) in neural networks of arbitrary complexity basing simulations on well-understood principles instead of vast collections of neuronal reconstructions (Markram et al., 2015).

Iterative growth models

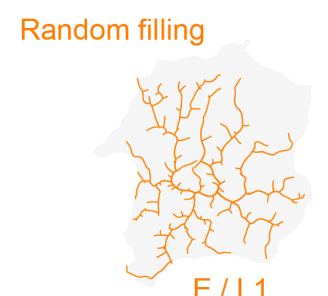

Maximal filling

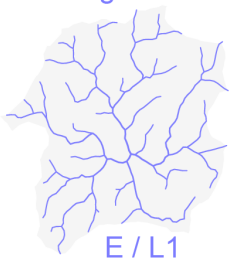

Mixed model

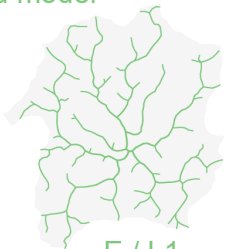

E / L1

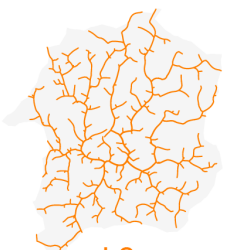

L2
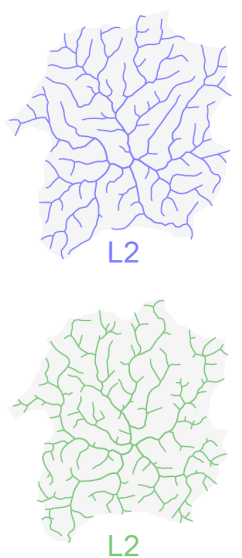

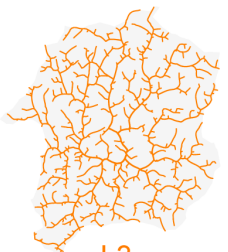

L3
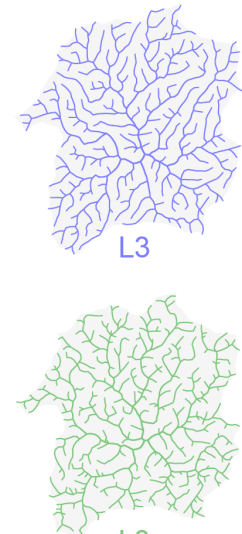

L3
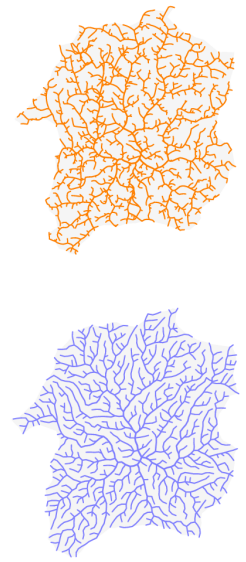

Scaling behaviour
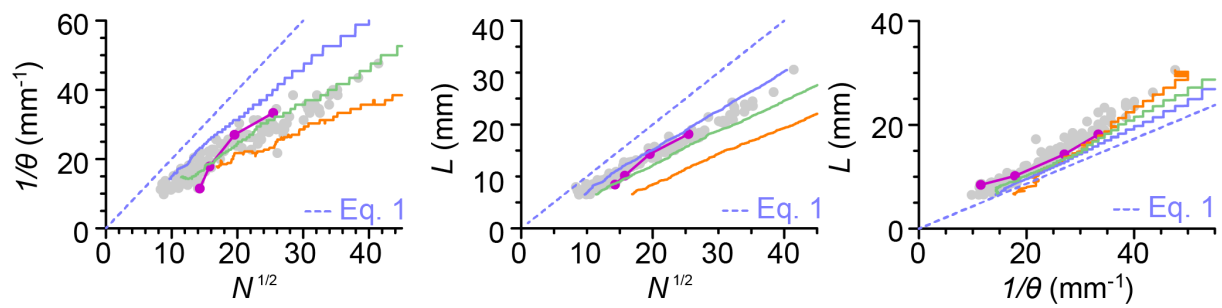

Fig 7. Morphological model of CIVda dendrite development.

Synthetic dendrites generated from scratch using the growth rules derived in Figure 6. Iterations shown correspond to total lengths of 9, 14, 20 and $30 \mathrm{~mm}$ approximating mean values for E/L1, L2, L3 and maximal length in L3 respectively after normalising $S$ from left to right with models that fill randomly (orange, top row), maximally (blue, middle row) and a mixed model (green, bottom row). Scaling behaviour (Bottom panels) is compared to the real cells (grey dots, otherwise similar to Figure 4). Straight lines (orange, green and blue) indicate the scaling behaviour during the growth iterations of the respective examples (random, maximal, mixed model filling) shown in Top panels. Pink line with dots shows the four (E, L1-L3) developmental stages of the same real cell from Figure 6. 

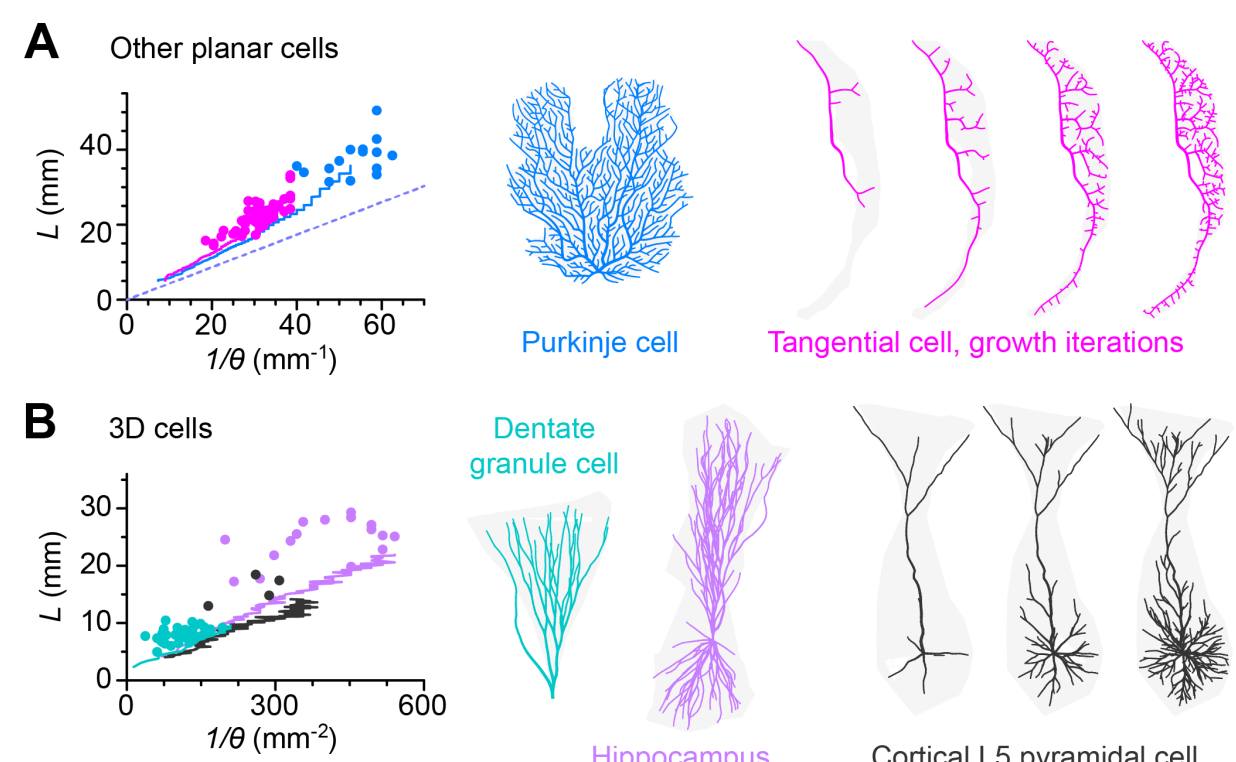

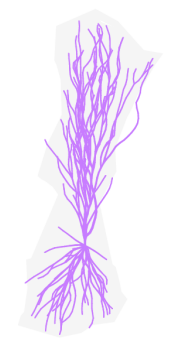

Hippocampus pyramidal cell

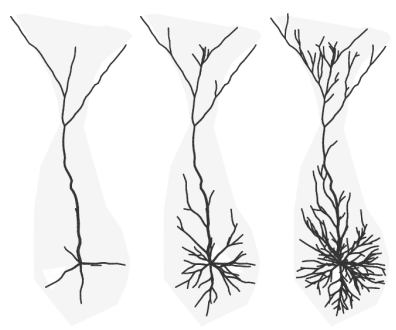

Cortical L5 pyramidal cell, growth iterations

Fig 8. Morphological model applied to other cell types.

A, Application of the same growth rule as in Figure 7 to other planar cells (blue, Purkinje cell; pink fly tangential cell; dots - data; lines - growth trajectories of sample synthetic morphologies shown to the right within the spanning areas - grey shaded - in which they were grown). B, Similar arrangement as in A but for 3D cells (dark cyan - dentate granule cell, dark grey - cortical layer 5 pyramidal cell, mauve - hippocampal pyramidal cell).

\section{Acknowledgments}

We are grateful to M. Schölvinck, P. Soba, T. Stürner and A. Ziegler for comments on the 168 manuscript. This work was supported by a BMBF grant (No. 01GQ1406 - Bernstein Award 169 2013) and a DFG grant (CU 217/2-1). The authors declare to have no competing financial 170 interests.

\section{Author contributions}

L.B., G.T. and H.C. designed the study. L.B. and G.T. designed and performed the experiments. 173 H.C. analysed the data, designed the growth model and performed all simulations. L.B., G.T. 174 and H.C. wrote the paper. 


\section{Materials and methods}

\section{Fly handling}

To label Class IV da (CIVda) neurons specifically, we used a fly strain that carried a fusion of a fraction of the enhancer of the $p p k$ gene and eGFP $\left(w^{1118} ; ; p p k-e G F P\right)$ (Grueber et al., 2003). This strain expresses eGFP in CIVda neurons from embryonic stage 16 throughout larval stages. We concentrated on the dorsal ddaC neuron (Grueber et al. 2002). For embryo collection, young fertilised females were placed in population cages, supplemented with apple agar plates maintained in an incubator at $25^{\circ} \mathrm{C}$ and $60 \%$ relative humidity. To obtain developmentally synchronised embryos the agar plate was supplemented with fresh yeast paste to promote laying of retained eggs and replaced after one hour. Females were then allowed to lay eggs for 30min. The collected eggs were placed back in the incubator and allowed to develop for $18 h$, when they were harvested, dechorionated with bleach for $3.5 \mathrm{~min}$ and rinsed with water. Not all embryos were dechorionated by this gentle treatment, and the chorion was then removed mechanically with a brush.

\section{Time-lapse image acquisition}

We developed a novel method to image the living larvae over several consecutive days causing as little interference as possible. Briefly, after each imaging session individuals were kept at $25^{\circ} \mathrm{C}$ and $60 \%$ relative humidity in a separate $500 \mu \mathrm{l}$ Eppendorf tube filled with $200 \mu \mathrm{l}$ standard cornmeal-agar fly food. To regain the test subject the fly food was dissolved in water and the larvae were localised under a binocular microscope (Figure 1A). To keep animals immobilised for imaging, but alive through the imaging sessions, we utilised three different physical immobilisation techniques at different stages. Embryo: We created a grid with 6 chambers of approximately $1 \mathrm{~mm} \times 0.5 \mathrm{~mm} \times 0.5 \mathrm{~mm}$ on an object slide using adhesive strip. Dechorionated embryos were placed in the grid, covered with halocarbon oil 700 (Sigma) and oriented in such a way that the dorsal class IV ddaC neurons faced towards the coverslip. L1 and L2 larvae: Images of L1 and L2 larvae were acquired under a custom-made object slide (Dimitrova et al. 2008). The metal custom object slide fitted a round coverslip onto which the larva was placed, oriented and covered with halocarbon oil. A plastic net on a round plastic support was then placed on top of the coverslip and fixed with screws to the metal slide. Detailed information about the design is available upon request. L3 larvae: L3 larvae were physically immobilised 
in halocarbon oil in-between an objective slide and a coverslip. Double-sided adhesive tape 206 served as spacer. On average two out of five individuals survived through all imaging steps. 207 During this procedure, development until the pupal stage was extended from typical five 208 days at $25^{\circ} \mathrm{C}$ to about seven days in our preparation. Given the increased development time in 209 these conditions from $\sim 120 h$ to $\sim 168 h$, embryo images were taken $18 h-19 h A E L$, L1 images $\quad 210$ at $42 h A E L, \mathrm{~L} 2$ at $90 h A E L$ and L3 images $138 h A E L$. The measured ddaC dendrite size at $90 h{ }_{21}$ and at $138 h$ corresponded to our previous measures of L2 and feeding L3 animals in control 212 conditions, respectively. Images were acquired with a Leica TCS SP2 Confocal Microscope ${ }_{213}$ (http://www. leica-microsystems.com), maintaining minimal laser intensity to reduce ${ }_{214}$ tissue damage. To avoid issues due to larval movement, we minimised imaging time per ${ }_{215}$ $z$-stack and thus chose a relatively large $z$-step of $2 \mu \mathrm{m}$ combined with a larger pinhole size ${ }_{216}$ $(85-150 \mu \mathrm{m})$ to obtain a voxel depth of $1.7-2.2 \mu \mathrm{m}$. For embryos, we used a $40 \times$ oil immersion 217 objective and for all the other stages a $20 \times$ oil immersion objective. ${ }_{218}$

\section{Data analysis}

All data analysis was performed in Matlab (www. mathworks. com) using our own software 220 package, the TREES toolbox (www.treestoolbox.org, version 1.15 and interim version, 221 Cuntz et al., 2010, 2011). A number of new TREES toolbox functions were custom-made 222 for this study and will be incorporated in the existing TREES toolbox with the publication ${ }_{223}$ of this work: span_tree, scaleS_tree, scaleV_tree, theta_tree, compare_tree, ui_comp_tree, 224 theta_mc_tree, growth_tree. See below for details on the individual functions. In the fol- 225 lowing italic function names with _tree suffix are TREES toolbox functions. All data will be made available on www. NeuroMorpho. Org and all code and data will be made available on WWW.treestoolbox.org.

\section{Anatomical data of CIVda neurons}

Image stacks from the confocal microscope were imported in the TREES toolbox and manual 230 reconstructions of all dendrites were performed individually (total amount of neurons $N={ }_{231}$ 168) using the dedicated reconstruction user interface cgui_tree. During the reconstruction 232 process we determined (1) adequate internode distances i.e. spatial resolution at which to ${ }_{233}$ resample (resample_tree) the dendritic structures, (2) parameters for a diameter taper toward ${ }_{234}$ the root (quaddiameter_tree) that best reproduced the overall diameter values of the real cells, 235 
(3) soma length and soma diameter values to best map soma diameters (soma_tree) post hoc on the existing reconstructions, and (4) region codes for dendrite, soma and axon. Axon nodes were discarded for the remaining analysis.

\section{Classical branching statistics}

A large palette of branching statistics were collected for each dendrite reconstruction separately using simple combinations of TREES toolbox functions: (1) Total dendrite length $L$ was the sum of all internode lengths (len_tree), (2) number of branch points $B$ were calculated as the sum of all nodes that are branch points (B_tree), (3) covered surface area $S$ was calculated with a novel custom written TREES toolbox function span_tree that counts 1 - bins after morphological closing with a disc of $4 \mu \mathrm{m}$ radius of a binary matrix with 1 - bins at tree node locations after resampling the trees to $1 \mu \mathrm{m}$ internode distances - similarly to previous work on fly lobula plate tangential cells (Cuntz et al., 2008), (4) Sholl analysis (Bird and Cuntz, 2019) that calculates the number of intersections of a tree with a growing circle centred on the dendrite root was done by using the dedicated TREES toolbox function sholl_tree, (5) normalised Sholl analysis was done by normalising the Sholl radii to $6 \times$ the mean Euclidean distance in the tree (eucl_tree) and normalising the number of intersections with the integral over the Sholl intersections diagram, (6) branch order distributions were calculated by identifying how many nodes and the overall dendritic cable length of their connected segments in the tree had a given branch order (BO_tree), (7) normalised branch orders were normalised to the next integer of $2.5 \times$ the mean branch order in any given tree and the cable distribution was normalised to the total length of dendrite, (8) branch length distributions were obtained by combining two TREES toolbox functions that calculate the path length from each node to the root (Pvec_tree) and that dissect the trees into their individual branches (dissect_tree), (9) normalised branch lengths were normalised to $3 \times$ the mean branch length in the tree and branch length frequency was normalised to the integral over the distribution, (10) compression value distributions were calculated as the ratio between Euclidean distances (eucl_tree) and the path distances (Pvec_tree) to the root for all nodes, (11) the Strahler order distributions were calculated as the percentages of dendrite length per given Strahler order (strahler_tree) (Vormberg et al. 2017), (12) branch angle distributions were obtained by calculating the angles in the branching plane of each branch point (angleB_tree). 


\section{Mathematical calculations for maximal space filling}

Iterating over $n$ and starting at $n=2$ we distribute $N=n^{2}$ targets on a hexagonal grid within diamond-shaped boundaries, $n$ being the number of targets on an edge of the diamond (Figure 3A). The targets form a space divided into equilateral triangles where neighbours are distance $l$ away from each other. If the basis of one triangle is set to be horizontal, the height of the equilateral triangle relates to $l$ with $h=\frac{\sqrt{3}}{2}$ and the total surface of the diamond is:

$$
S=h \cdot(n-1)^{2} \cdot l^{2}
$$

Circles of radius $\theta=\frac{l}{2}$ surrounding the targets on the hexagonal grid are packed optimally 274 and fill the surface area. It can easily be shown that the surface area covered by the circles 275 within the diamond shape follows $S^{\prime}=(n-1)^{2} \times$ the surface of the circle since the four 276 corners together cover the surface of one circle, each edge point covers half of a circle and 277 each centre point covers one entire circle each, so:

$$
S^{\prime}=\frac{\pi}{4}(n-1)^{2} \cdot l^{2}
$$

which corresponds to a portion of $\frac{\pi}{2 \sqrt{3}} \approx 90.69 \%$ of the total surface $S$ (see Equation 2).

$$
\theta=\frac{h^{-\frac{1}{2}}}{2} \cdot S^{\frac{1}{2}} \cdot N^{-\frac{1}{2}}
$$

Connecting the points on the grid optimally (in terms of total length of cable) yields a tree with length $L=(N-1) \cdot l$ since for each target (except the first) exactly one piece of length $l$ is required to connect it to the rest of the tree. Note that the minimum spanning tree has many solutions since all the distances between neighbours are equal, being precisely $l$. An inherent relation exists between $L$ and $\theta$ : 


$$
L=2(N-1) \cdot \theta
$$

Combining $L=(N-1) \cdot l$ with $N=n^{2}$ and Equation 2 results in

$$
L=h^{-\frac{1}{2}} \cdot S^{\frac{1}{2}} \cdot \frac{\left(n^{2}-1\right)}{(n-1)} \approx h^{-\frac{1}{2}} \cdot S^{\frac{1}{2}} \cdot N^{\frac{1}{2}}
$$

reminiscent of the power law that we described previously for planar dendritic minimum spanning trees generally (Cuntz et al., 2012) and in this case providing an upper bound.

$$
\theta \approx \frac{S}{2 \cdot h \cdot L}
$$

For a $2 D$ square grid, the equations are similar although the coverage $\frac{S^{\prime}}{S}=\frac{\pi}{4} \approx 78.54 \%$ is not as good with:

$$
S=(n-1)^{2} \cdot l^{2} \quad \theta=\frac{1}{2} \cdot S^{\frac{1}{2}} \cdot N^{-\frac{1}{2}} \quad L \approx S^{\frac{1}{2}} \cdot N^{\frac{1}{2}} \quad \theta \approx \frac{S}{2 \cdot L}
$$

while $N=n^{2}, \theta=\frac{l}{2}$, and $S^{\prime}=\frac{\pi}{4}(n-1)^{2} \cdot l^{2}$ remain unchanged.

Similarly, a $3 D$ cubic grid can be constructed with:

$$
V=(n-1)^{3} \cdot l^{3} \quad \theta=\frac{1}{8} \cdot V^{\frac{1}{3}} \cdot N^{-\frac{1}{3}} \quad L \approx V^{\frac{1}{3}} \cdot N^{\frac{2}{3}} \quad \theta \approx \frac{1}{8} \cdot V^{\frac{1}{2}} \cdot L^{-\frac{1}{2}}
$$

and $N=n^{3}, \theta=\frac{l}{2}, V^{\prime}=\frac{\pi}{6}(n-1)^{3} \cdot l^{3}$ and a poorer coverage even of $\frac{V^{\prime}}{V}=\frac{\pi}{6} \approx 52.36 \%$ and a $\frac{2}{3}$ power between $N$ and $L$ as we have shown previously for $3 D$ cases (Cuntz et al., 2012). 


\section{Scaling of real trees}

In order to compare real trees with our simple maximal space filling example, all reconstruc- 304 tions were scaled to the same surface area $S$ as our reference diamond $\left(h \cdot 1,000,000 \mu m^{2}\right)$ by 305 scaling the trees twice while measuring $S$ (span_tree, see above) to make sure that target $S$ is reached precisely in all cases (new TREES toolbox function scaleS_tree). Real trees in Figures $3 \mathrm{C}, 4,6,7,7$ and 8 were scaled in such a manner.

\section{Space-filling measure $\frac{1}{\theta}$}

A custom-written new TREES toolbox function theta_tree was used to calculate how space filling a tree is. $\theta$ is the distance one has to move away from the tree to cover $90.69 \%$ of the spanning surface of the tree, in analogy to our maximal space filling mathematical framework, see above. Similarly to calculating the surface area $S$ we calculated a binary matrix with 1 - bins after morphological closing with a disc of $4 \mu \mathrm{m}$ radius and used the Matlab function bwdist to calculate the distance from each bin within this spanning area and the closest bin occupied by the dendritic tree. This approach would allow comparing distance distributions in histograms, which for the example in Figure 6 would yield similar results as comparing single values of $\theta$ (not shown). The iterative growth process followed a slightly different but equivalent approach using a Monte Carlo method since for 3D cases the binary matrices would have been very large (see below).

\section{Dendritic minimum spanning trees}

Optimal wiring was implemented as previously described (Cuntz et al. 2007) to minimise ${ }_{322}$ total cable length with a minimum spanning tree algorithm connecting a given set of targets. ${ }_{223}$ Similarly here an additional cost to reduce path lengths to any target along the tree towards 324 the root of the tree was required. This second cost was weighted by the balancing factor $b f$, the ${ }_{325}$ only parameter that the wiring algorithm takes: total cost $=$ wiring cost $+b f \cdot$ path length cost. ${ }^{326}$ This method was successfully used previously (Cuntz et al., 2008, 2010) and all algorithms ${ }_{327}$ are available in the TREES toolbox (www.treestoolbox.org, MST_tree). Targets were dis- ${ }_{328}$ tributed uniformly in the target area and connected with the minimum spanning tree. Two ${ }_{329}$ different configurations were used, see the following two paragraphs. 


\section{Random morphological model}

To validate that real dendrites were all well represented by optimal wiring on randomly 332 distributed targets we distributed targets randomly uniformly in the surface area of each real dendrite one at a time (Figure 3D). We generated minimum spanning trees connecting as many targets as required to reproduce the number of branch points $B$ in the original tree and matched the resulting synthetic tree surface area $S$ each using the same scaling procedure used for real reconstructions (see above). We then scanned the parameter $b f$ of the model between 0 and 1 in steps of 0.025. An error function comparing mean total length, branch order, compression and path length between synthetic trees and their real counterparts yielded an optimal $b f$ of 0.225 . The corresponding synthetic trees were then used with this $b f$ value (Figure 3D). For visual purposes, all synthetic trees were smoothed (smooth_tree), and a slight jitter was added (jitter_tree) that did not affect the branching statistics.

\section{Scaling model}

In a simplified model that reproduced the scaling behaviour of real dendrites precisely, we distributed random targets uniformly in the diamond area of our maximal space-filling model (Figure 3B). Targets were connected using the same minimum spanning tree as above (MST_tree) with $b f=0.225$ obtained from the random morphological model. These simplified trees were used with the original surface area $\left(h \cdot 1,000,000 \mu m^{2}\right)$ for Figures $3 \mathbf{B}$, and $4 \mathbf{A}$. In a simple modification of this configuration for Figure $4 \mathbf{B}$ the number of targets $N$ (from 130 to 1,700 in steps of 50 ) scaled with the side $S^{\frac{1}{2}}$ of a square area (from $67.5 \mu m$ to $765.0 \mu m$ in steps of $22.5 \mu \mathrm{m}$ ) with an initial phase with constant branch point numbers for the embryo case $\left(N=130\right.$ for $S^{\frac{1}{2}}=22.5 \mu \mathrm{m}$ and $\left.45.0 \mu \mathrm{m}\right)$ to simulate the phase transition.

\section{Time-lapse analysis}

Before registration of the branch and termination points, the morphologies of identified pairs 354 of dendrites (the same cell in two consecutive time steps, $N=47$ pairs) we rotated, translated 355 and scaled them separately in both dimensions to maximise the overlap of dendritic branches. 356 Branch and termination points were then registered using first a custom written algorithm that 357 compared paths and topological order of all nodes in the two dendrites (new TREES toolbox function compare_tree). The preliminary registration was then corrected by a custom-written 
points of both time points to one another. For the stretching analysis, the individual scaling 361 steps were ignored and the vectors were drawn between branch and termination points of 362 time points 1 and 2 for all pairs. Newly formed branches or disappearing branches were ${ }_{363}$ ignored. For the space filling analysis, only new branches in time point 2 were considered $-{ }_{364}$ disappearing branches were negligible -- that appeared within the confines (tight hull using 365 Matlab function boundary with parameter alpha $=0.5$ ) of branch and termination points in 366 time point 1 . This constraint was necessary because in some cases an entire region of the distal 367 dendrite became visible only in the time point 2 reconstruction. Values for $\theta, N$ and $L$ were 368 calculated similarly to reconstructions in Figure 3.

\section{Iterative growth model}

The iterative growth model (new TREES function growth_tree) was fit to reproduce the ${ }_{371}$ statistics of dendritic reconstructions in time point 2 given the reconstruction in time point 1372 as a starting point (Figure 6). The iterations were subsequently used to grow entire trees from ${ }^{373}$ scratch. At each time point, the surface area (or spanning volume for $3 D$ cases) was probed ${ }_{374}$ with 25,000 random points (or 100,000 in the $3 D$ cases). For each probe, the nearest distance 375 eucl to the tree was detected. The resulting distances were capped at a maximal growth range 376 radius $(120 \mu \mathrm{m})$ and normalised to the maximum distance. In a mixed model, the selected probing point was calculated by finding the maximum of $(k \cdot R+(1-k) \cdot e u c l)$ for $k$ the amount of noise between 0 and 1 and $R$ a random number between 0 and 1 for each probing point. The noise parameter $k$ was saturated using $\tanh (8 \cdot k)$. In the random filling model (orange, Figure 6) one probing point was chosen at random $(k=1)$. In the maximal filling model (blue, Figure 6) the probing point with the maximum distance was selected $(k=0)$. In the mixed model, $k$ was chosen as 0.45 . The selected probing point was then connected to the closest point on the tree according to cable length and path length cost with a $b f=0.225$. The new branch was subdivided into $1 \mu \mathrm{m}$ segments and jittered slightly before the next iteration started. The growth process stopped when a target $L$ was reached, in this case, the length of the tree in time point 2 or the length of the tree that was simulated. At each iteration $L$ and $N$ were stored and $\theta$ was calculated in this case as the largest value in eucl among the $90.69 \%$ lowest values of eucl. 


\section{Synthetic morphologies of other planar and 3D dendrites}

Five synthetic dendrites were grown from scratch using the growth_tree iterative growth model. Synthetic mouse cerebellar Purkinje cells (Martone et al., 2003) were obtained using $b f=0.6$, radius $=450 \mu m, k=0.15$; Fly lobula plate tangential cells (Cuntz et al., 2008) were obtained using $b f=0.175$, radius $=800 \mu m, k=0.45$; Rat dentate granule cells (Rihn and Claiborne, 1990) were obtained using $b f=0.935$, radius $=500 \mu m, k=0.40$; Guinea pig hippocampus pyramidal cells (Wittner and Miles, 2007) were obtained using $b f=0.935$, radius $=1,000 \mu m, k=0.45$; Rat cortical layer 5 pyramidal cells (Hay et al., 2013) were obtained using $b f=0.75$, radius $=750 \mu m, k=0.30$.

\section{References}

Bird AD, Cuntz H (2019) Dissecting Sholl analysis into its functional components. Cell 400 Reports 27:3081-3096.e5.

Chalmers K, Kita EM, Scott EK, Goodhill GJ (2016) Quantitative analysis of axonal branch 402 dynamics in the developing nervous system. PLoS Computational Biology 12:e1004813. ${ }^{403}$

Cuntz H, Borst A, Segev I (2007) Optimization principles of dendritic structure. Theoretical 404 Biology and Medical Modelling 4:21.

Cuntz H, Forstner F, Borst A, Häusser M (2010) One rule to grow them all: A general theory 406 of neuronal branching and its practical application. PLoS Computational Biology 6:e1000877. 407

Cuntz H, Forstner F, Borst A, Häusser M (2011) The TREES toolbox-probing the basis of 408 axonal and dendritic branching. Neuroinformatics 9:91-96.

Cuntz H, Forstner F, Haag J, Borst A (2008) The morphological identity of insect dendrites. 410 PLoS Computational Biology 4:e1000251.

Cuntz H, Forstner F, Schnell B, Ammer G, Raghu SV, Borst A (2013) Preserving neural function 412 under extreme scaling. PLOS ONE 8:e71540.

Cuntz H, Mathy A, Häusser M (2012) A scaling law derived from optimal dendritic wiring. ${ }^{414}$ PNAS 109:11014-11018. 
Denk W, Briggman KL, Helmstaedter M (2012) Structural neurobiology: missing link to a 416 mechanistic understanding of neural computation. Nature Reviews Neuroscience 13:351-358. 417

Dimitrova S, Reissaus A, Tavosanis G (2008) Slit and Robo regulate dendrite branching and ${ }_{418}$ elongation of space-filling neurons in Drosophila. Developmental Biology 324:18-30. $\quad 419$

Ganguly S, Trottier O, Liang X, Bowne-Anderson H, Howard J (2016) Morphology of fly larval ${ }_{420}$ class IV dendrites accords with a random branching and contact based branch deletion ${ }_{421}$ model. Arxiv p. 1611.05918.

Gerhard S, Andrade I, Fetter RD, Cardona A, Schneider-Mizell CM (2017) Conserved neural ${ }_{423}$ circuit structure across Drosophila larval development revealed by comparative connec- ${ }_{424}$ tomics. eLife 6:e29089. ${ }_{425}$

Grueber WB, Jan LY, Jan YN (2002) Tiling of the Drosophila epidermis by multidendritic ${ }_{426}$ sensory neurons. Development 129:2867-2878.

Grueber WB, Ye B, Moore AW, Jan LY, Jan YN (2003) Dendrites of distinct classes of ${ }_{428}$ Drosophila sensory neurons show different capacities for homotypic repulsion. Current ${ }_{429}$ Biology 13:618-626. ${ }_{430}$

Hales TC (2000) Cannonballs and honeycombs. Notices of the American Mathematical Soci- ${ }_{431}$ ety $47: 440-449$.

Hattori D, Chen Y, Matthews BJ, Salwinski L, Sabatti C, Grueber WB, Zipursky SL (2009) ${ }_{433}$ Robust discrimination between self and non-self neurites requires thousands of Dscam1 ${ }_{434}$ isoforms. Nature 461:644-648.

Hay E, Schürmann F, Markram H, Segev I (2013) Preserving axosomatic spiking features ${ }_{436}$ despite diverse dendritic morphology. Journal of Neurophysiology 109:2972-2981.

He HY, Cline HT (2011) Diadem X: automated 4 dimensional analysis of morphological data. ${ }^{438}$ Neuroinformatics 9:107-112.

Iyer EPR, Iyer SC, Sullivan L, Wang D, Meduri R, Graybeal LL, Cox DN (2013) Functional 440 genomic analyses of two morphologically distinct classes of Drosophila sensory neurons: ${ }^{441}$ post-mitotic roles of transcription factors in dendritic patterning. PloS one 8:e72434. ${ }_{442}^{4}$ 
Jan YN, Jan LY (2010) Branching out: mechanisms of dendritic arborization. Nature Reviews ${ }_{443}$ Neuroscience 11:316-328.

Jiang N, Soba P, Parker E, Kim CC, Parrish JZ (2014) The microRNA bantam regulates a ${ }_{445}$ developmental transition in epithelial cells that restricts sensory dendrite growth. Develop- ${ }_{446}$ ment 141:2657-2668.

Koene RA, Tijms B, van Hees P, Postma F, De Ridder A, Ramakers GJA, Van Pelt J, Van Ooyen ${ }_{448}$ A (2009) NETMORPH: A framework for the stochastic generation of large scale neuronal ${ }_{449}$ networks with realistic neuron morphologies. Neuroinformatics 7:195-210.

Lee PC, He HY, Lin Cy, Ching Yt, Cline HT (2013) Computer aided alignment and quantitative ${ }_{451}$ 4D structural plasticity analysis of neurons. Neuroinformatics 11:249-257.

Luczak A (2006) Spatial embedding of neuronal trees modeled by diffusive growth. Journal of ${ }_{453}$ Neuroscience Methods 157:132-141.

Markram H, Muller E, Ramaswamy S, Reimann MW, Abdellah M, Sanchez CA, Ailamaki ${ }_{455}$ A, Alonso-Nanclares L, Antille N, Arsever S, Kahou GAA, Berger TK, Bilgili A, Buncic N, ${ }^{456}$ Chalimourda A, Chindemi G, Courcol JD, Delalondre F, Delattre V, Druckmann S, Dumusc ${ }_{457}$ R, Dynes J, Eilemann S, Gal E, Gevaert ME, Ghobril JP, Gidon A, Graham JW, Gupta A, ${ }_{458}$ Haenel V, Hay E, Heinis T, Hernando JB, Hines M, Kanari L, Keller D, Kenyon J, Khazen G, 459 Kim Y, King JG, Kisvarday Z, Kumbhar P, Lasserre S, Le Bé JV, Magalhães BRC, Merchán- 460 Pérez A, Meystre J, Morrice BR, Muller J, Muñoz-Céspedes A, Muralidhar S, Muthurasa K, ${ }_{461}$ Nachbaur D, Newton TH, Nolte M, Ovcharenko A, Palacios J, Pastor L, Perin R, Ranjan R, ${ }_{62}$ Riachi I, Rodríguez JR, Riquelme JL, Rössert C, Sfyrakis K, Shi Y, Shillcock JC, Silberberg G, 463 Silva R, Tauheed F, Telefont M, Toledo-Rodriguez M, Tränkler T, Van Geit W, Díaz JV, Walker ${ }^{464}$ R, Wang Y, Zaninetta SM, DeFelipe J, Hill SL, Segev I, Schürmann F (2015) Reconstruction ${ }_{465}$ and simulation of neocortical microcircuitry. Cell 163:456-492.

Martone ME, Zhang S, Gupta A, Qian X, He H, Price DL, Wong M, Santini S, Ellisman ${ }_{467}$ MH (2003) The cell-centered database: a database for multiscale structural and protein 468 localization data from light and electron microscopy. Neuroinformatics 1:379-395. 469

Matthews BJ, Kim ME, Flanagan JJ, Hattori D, Clemens JC, Zipursky SL, Grueber WB (2007) 470 Dendrite self-avoidance is controlled by Dscam. Cell 129:593-604. 
Memelli H, Torben-Nielsen B, Kozloski J (2013) Self-referential forces are sufficient to explain 472 different dendritic morphologies. Frontiers in Neuroinformatics 7:1.

Nanda S, Das R, Bhattacharjee S, Cox DN, Ascoli GA (2018) Morphological determi- 474 nants of dendritic arborization neurons in Drosophila larva. Brain Structure E Func- 475 tion 223:1107-1120.

Nicosia V, Vértes PE, Schafer WR, Latora V, Bullmore ET (2013) Phase transition in the 477 economically modeled growth of a cellular nervous system. PNAS 110:7880-7885. 478

Parrish JZ, Emoto K, Kim MD, Jan YN (2007) Mechanisms that regulate establishment, 479 maintenance, and remodeling of dendritic fields. Annual Review of Neuroscience 30:399-423. 480

Parrish JZ, Xu P, Kim CC, Jan LY, Jan YN (2009) The microRNA bantam functions in ep- 481 ithelial cells to regulate scaling growth of dendrite arbors in drosophila sensory neurons. ${ }_{482}$ Neuron 63:788-802.

Peng Y, Lee J, Rowland K, Wen Y, Hua H, Carlson N, Lavania S, Parrish JZ, Kim MD ${ }^{484}$ (2015) Regulation of dendrite growth and maintenance by exocytosis. Journal of Cell 485 Science 128:4279-4292.

Rihn LL, Claiborne BJ (1990) Dendritic growth and regression in rat dentate granule cells ${ }_{487}$ during late postnatal development. Developmental Brain Research 54:115-124.

Schröter M, Paulsen O, Bullmore ET (2017) Micro-connectomics: probing the organization of ${ }_{489}$ neuronal networks at the cellular scale. Nature Reviews Neuroscience 18:131-146.

Shimono K, Sugimura K, Kengaku M, Uemura T, Mochizuki A (2010) Computational modeling of dendritic tiling by diffusible extracellular suppressor. Genes to Cells 15:137-149.

Soba P, Zhu S, Emoto K, Younger S, Yang SJ, Yu HH, Lee T, Jan LY, Jan YN (2007) Drosophila 493 sensory neurons require Dscam for dendritic self-avoidance and proper dendritic field ${ }^{494}$ organization. Neuron 54:403-416.

Stepanyants A, Hof PR, Chklovskii DB (2002) Geometry and structural plasticity of synaptic connectivity. Neuron 34:275-288.

Sugimura K, Shimono K, Uemura T, Mochizuki A (2007) Self-organizing mechanism for development of space-filling neuronal dendrites. PLoS Computational Biology 3:e212. 
Tavosanis G (2012) Dendritic structural plasticity. Developmental Neurobiology 72:73-86.

Vormberg A, Effenberger F, Muellerleile J, Cuntz H (2017) Universal features of dendrites 501 through centripetal branch ordering. PLoS computational biology 13:e1005615.

Watson HW, Galton F (1875) On the Probability of the Extinction of Families. The Journal of the ${ }^{503}$ Anthropological Institute of Great Britain and Ireland 4:138-144.

Wen Q, Chklovskii DB (2008) A cost-benefit analysis of neuronal morphology. Journal of 505 Neurophysiology 99:2320-2328.

Wittner L, Miles R (2007) Factors defining a pacemaker region for synchrony in the hippocam- 507 pus. Journal of Physiology 584:867-883.

Yalgin C, Ebrahimi S, Delandre C, Yoong LF, Akimoto S, Tran H, Amikura R, Spokony R, 509 Torben-Nielsen B, White KP, Moore AW (2015) Centrosomin represses dendrite branching 510 by orienting microtubule nucleation. Nature Neuroscience 18:1437-1445. 


\section{Appendix}

Figures 1-8 Overview of all reconstructions showing maximum intensity projections of the microscopy image stacks and the skeletons of all relevant reconstructions (red - dendrite, green - soma, blue - axon). The reconstructions are ordered by specimen (e.g. \#9A) and by developmental stages (Embryo, Larval Instar 1-3). All reconstructions are labelled by larval segment identifiers (e.g. 31, 41, 5l, and 3r, 4r, 5r). The maximum intensity projections are shown for multiple tiled stacks when available. The reconstructions were not necessarily done in the shown image stack since in the overlap region of neighbouring tiled image stacks only one image can be shown.

Figures 9-12 Overview of skeletons for all individual reconstructions, scaled to cover the same surface area (contour is drawn in light grey). Soma location is shown with a large dot. Dark grey shaded area indicates the $\sim 10 \%$ of the surface area that is furthest away $(>\theta)$ from the tree. Specimen number, developmental stage and segment identifier (similar to Appendix Figures 1-8) are shown under each reconstruction.

Figures 13-16 Overview of all pairs of reconstructions (left - time 1; right - time 2) for which the same cell was imaged at two consecutive developmental stages. Registered branch and termination points in each pair are shown with the same colour. Shaded area indicates the conserved spanning area from time 1 in the reconstruction at time 2 . Differences in the spanning area can be due to occlusion in time 1 and only the new branches within the spanning area of time 1 were used for the time-lapse analysis in Figures 5 and 6 . 
bioRxiv preprint doi: https://doi.org/10.1101/2020.07 07.191064; this version posted July 7, 2020. The copyright holder for this preprint (which was not certified by peer review) is the author/funder, who has granted bioRxiv a license to display the preprint in perpetuity. It is made available under aCC-BY-NC-ND 4.0 International license.

Dendrite growth rule

Baltruschat, Tavosanis \& Cuntz
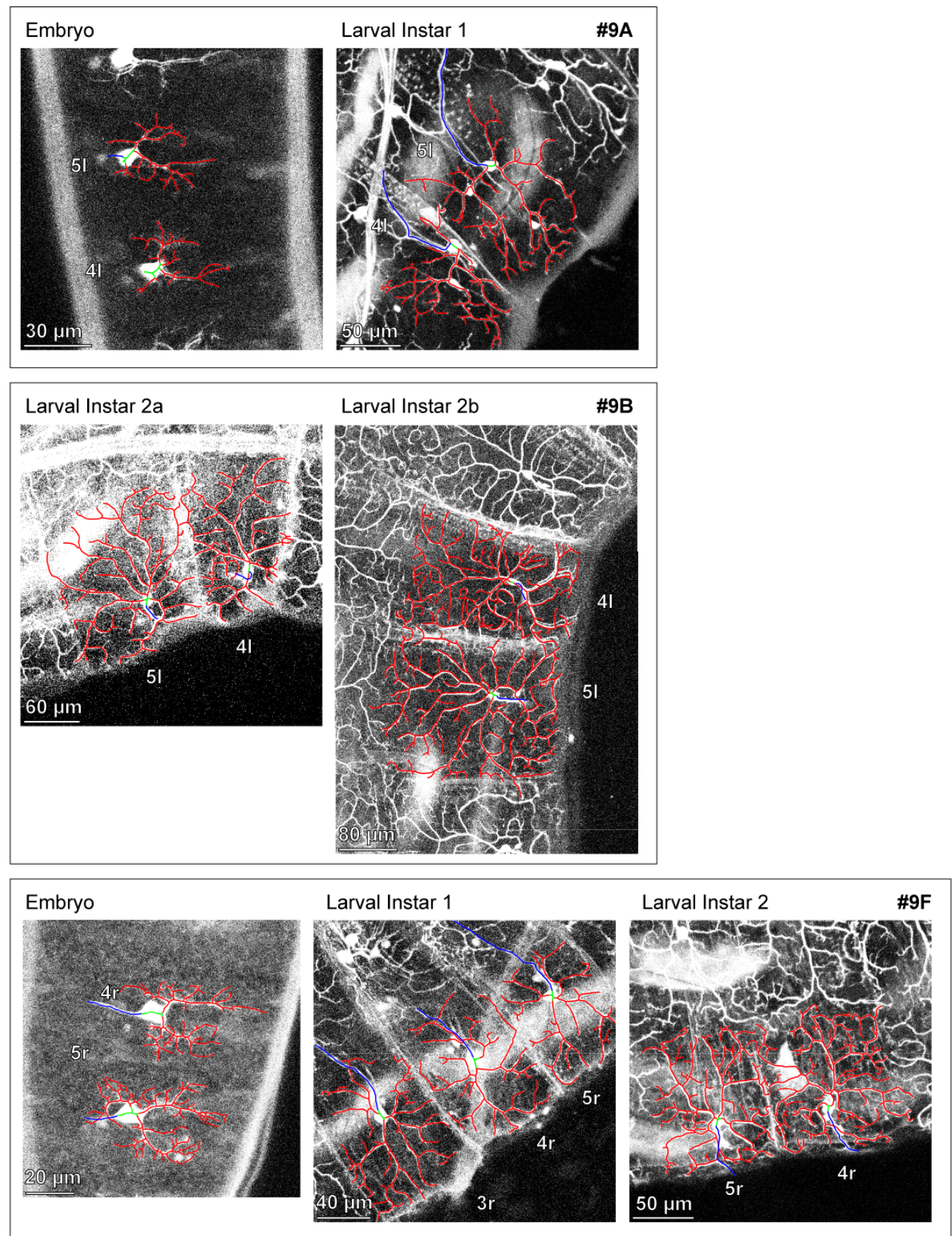

Figure Appendix 1 
bioRxiv preprint doi: https://doi.org/10.1101/2020.07.07.191064; this version posted July 7, 2020. The copyright holder for this preprint (which was not certified by peer review) is the author/funder, who has granted bioRxiv a license to display the preprint in perpetuity. It is made available under aCC-BY-NC-ND 4.0 International license.

Dendrite growth rule

Baltruschat, Tavosanis \& Cuntz
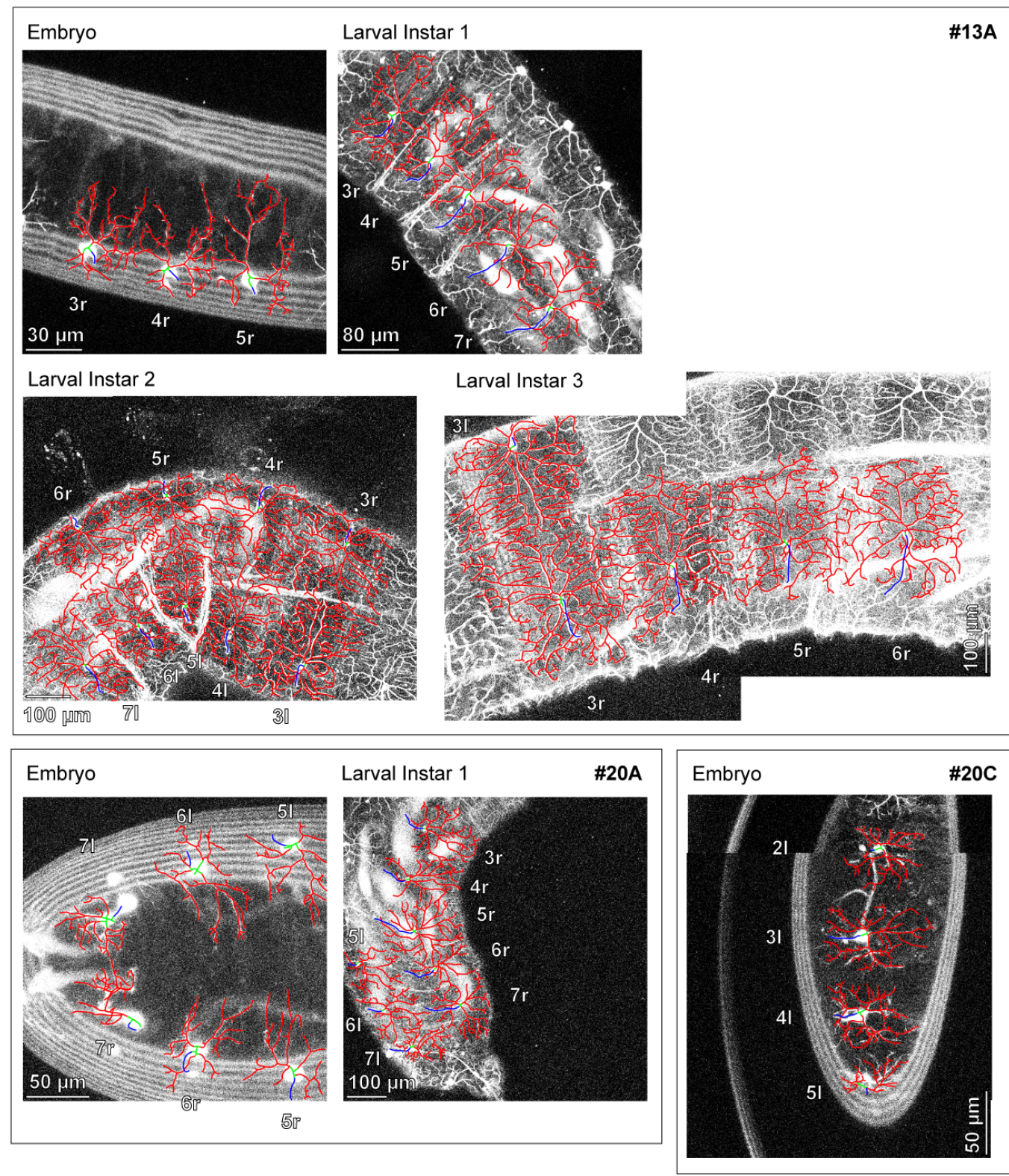

Figure Appendix 2 
bioRxiv preprint doi: https://doi.org/10.1101/2020.07.07.191064; this version posted July 7, 2020. The copyright holder for this preprint (which was not certified by peer review) is the author/funder, who has granted bioRxiv a license to display the preprint in perpetuity. It is made available under aCC-BY-NC-ND 4.0 International license.

Dendrite growth rule

Baltruschat, Tavosanis \& Cuntz

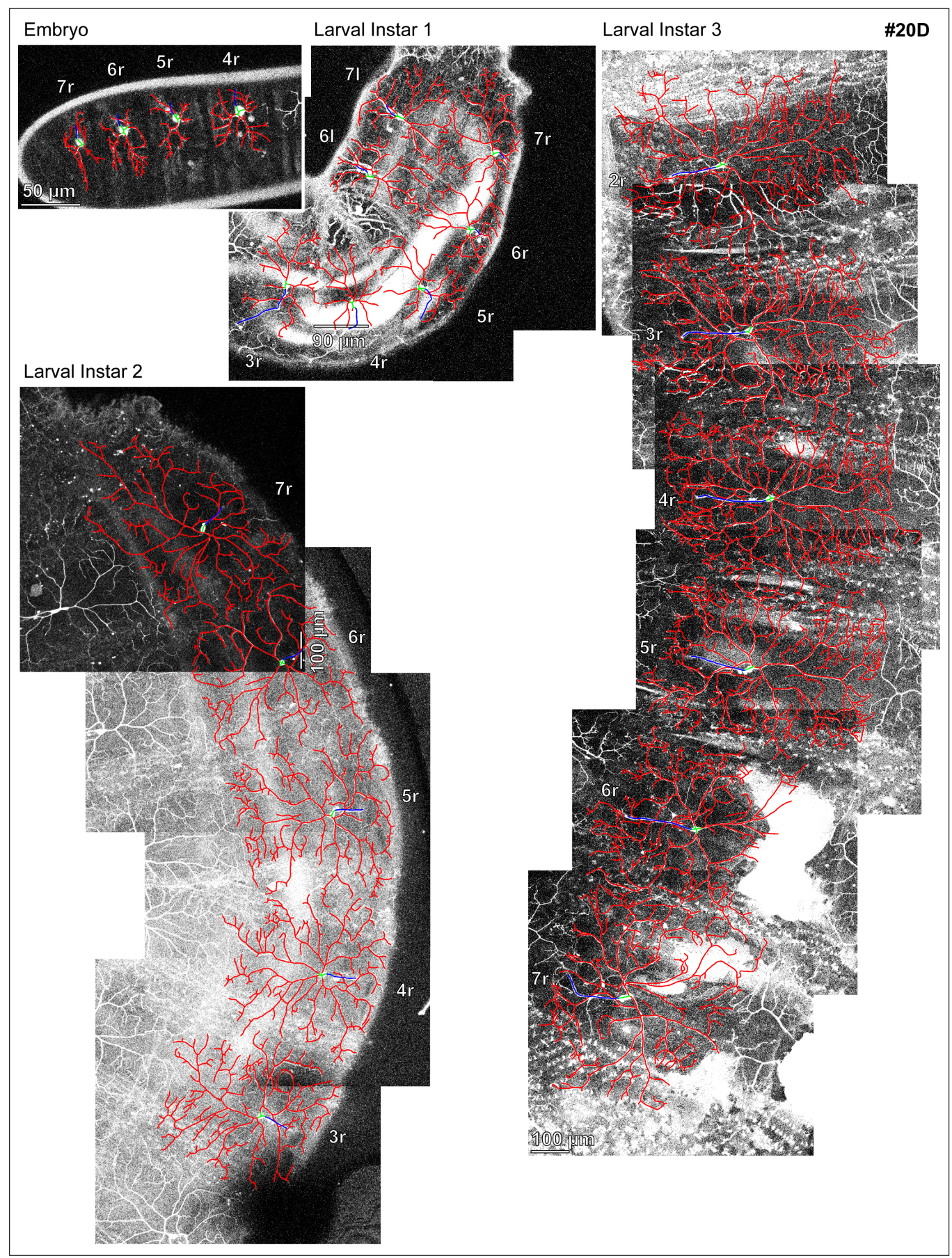

Figure Appendix 3 
bioRxiv preprint doi: https://doi.org/10.1101/2020.07 07.191064; this version posted July 7 , 2020. The copyright holder for this preprint (which was not certified by peer review) is the author/funder, who has granted bioRxiv a license to display the preprint in perpetuity. It is made available under aCC-BY-NC-ND 4.0 International license.

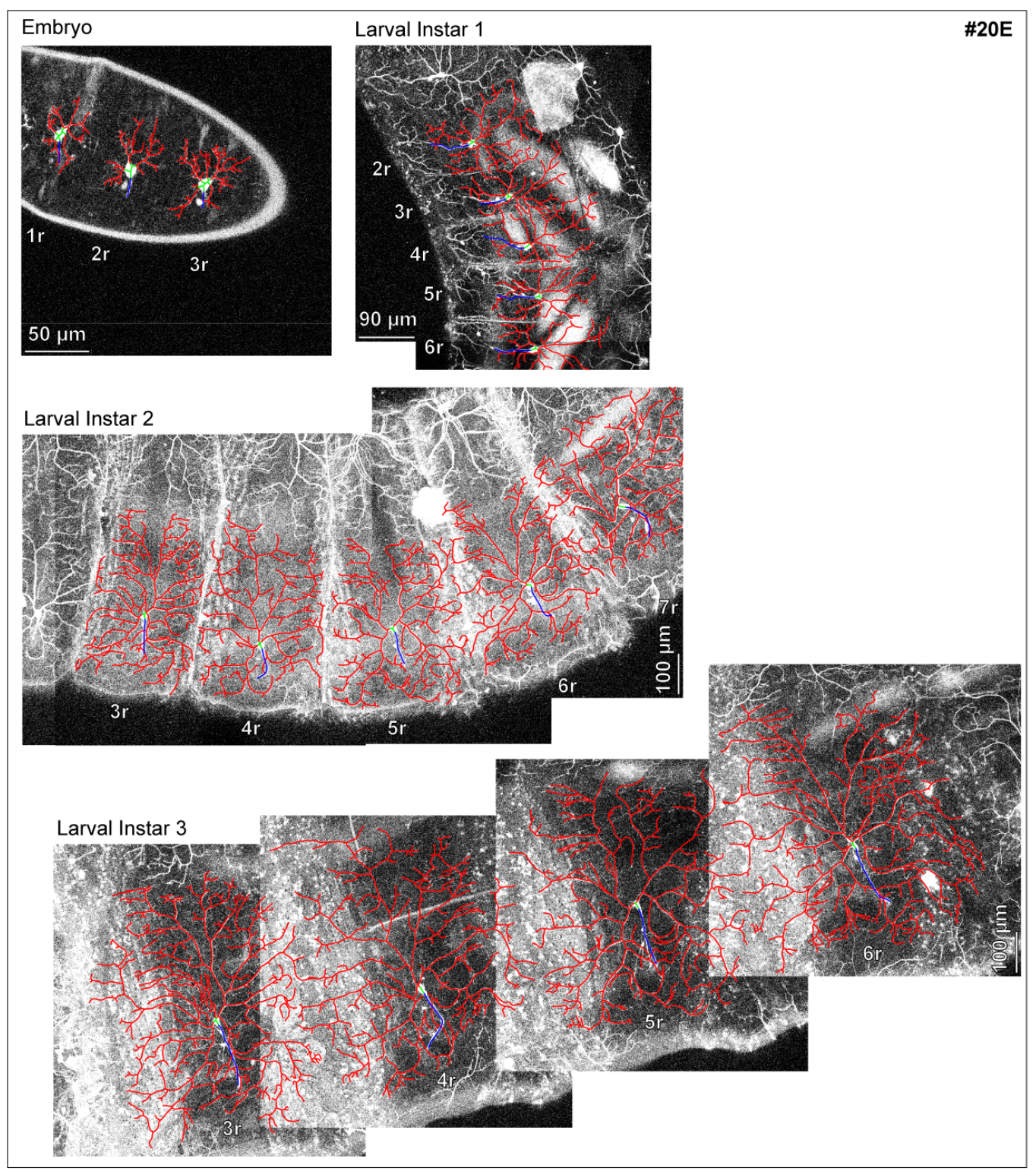

Figure Appendix 4 
bioRxiv preprint doi: https://doi.org/10.1101/2020.07.07.191064; this version posted July 7, 2020. The copyright holder for this preprint (which was not certified by peer review) is the author/funder, who has granted bioRxiv a license to display the preprint in perpetuity. It is made available under aCC-BY-NC-ND 4.0 International license.
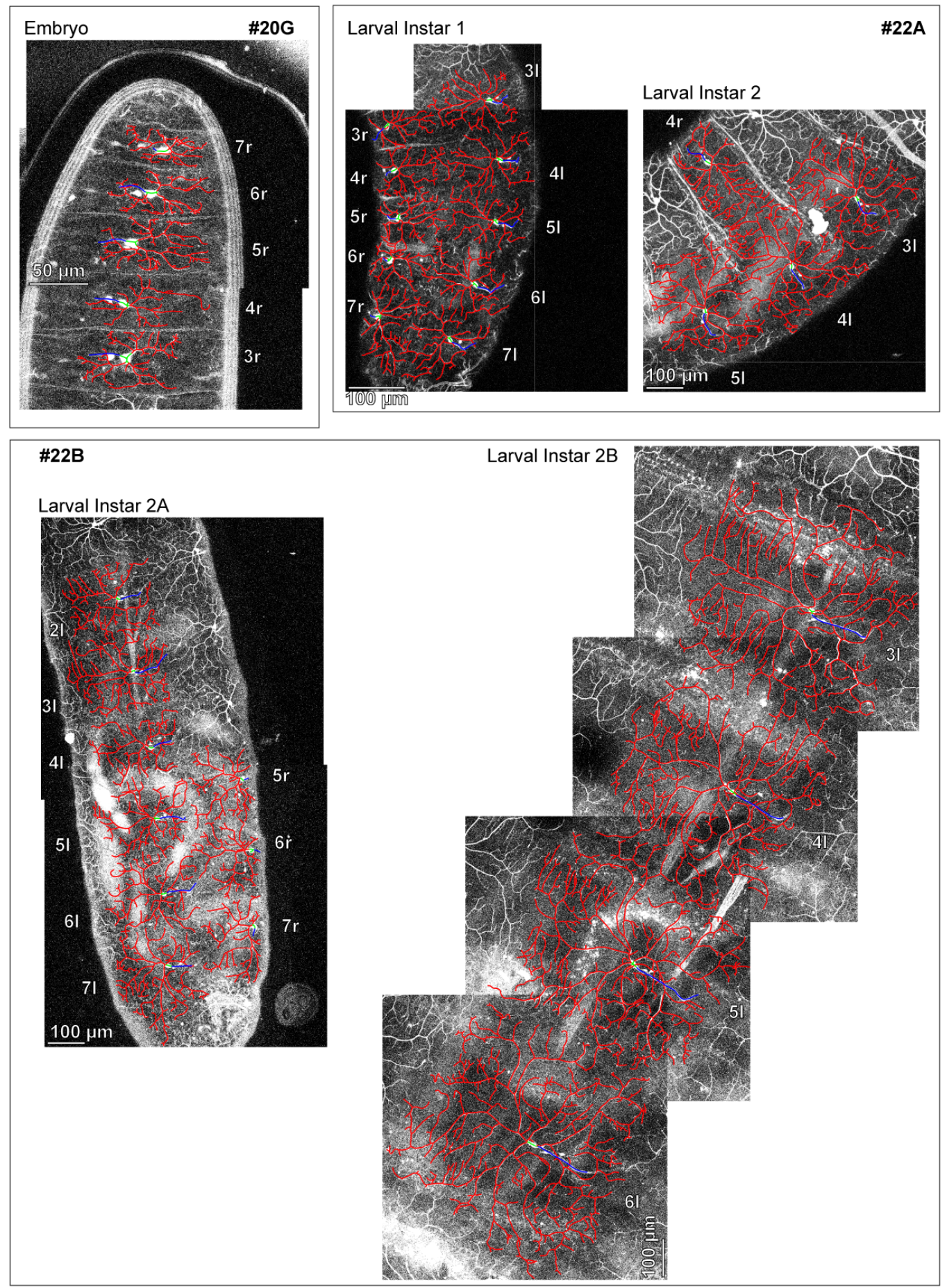

Figure Appendix 5 
bioRxiv preprint doi: https://doi.org/10.1101/2020.07 07.191064; this version posted July 7, 2020. The copyright holder for this preprint (which was not certified by peer review) is the author/funder, who has granted bioRxiv a license to display the preprint in perpetuity. It is made available under aCC-BY-NC-ND 4.0 International license.

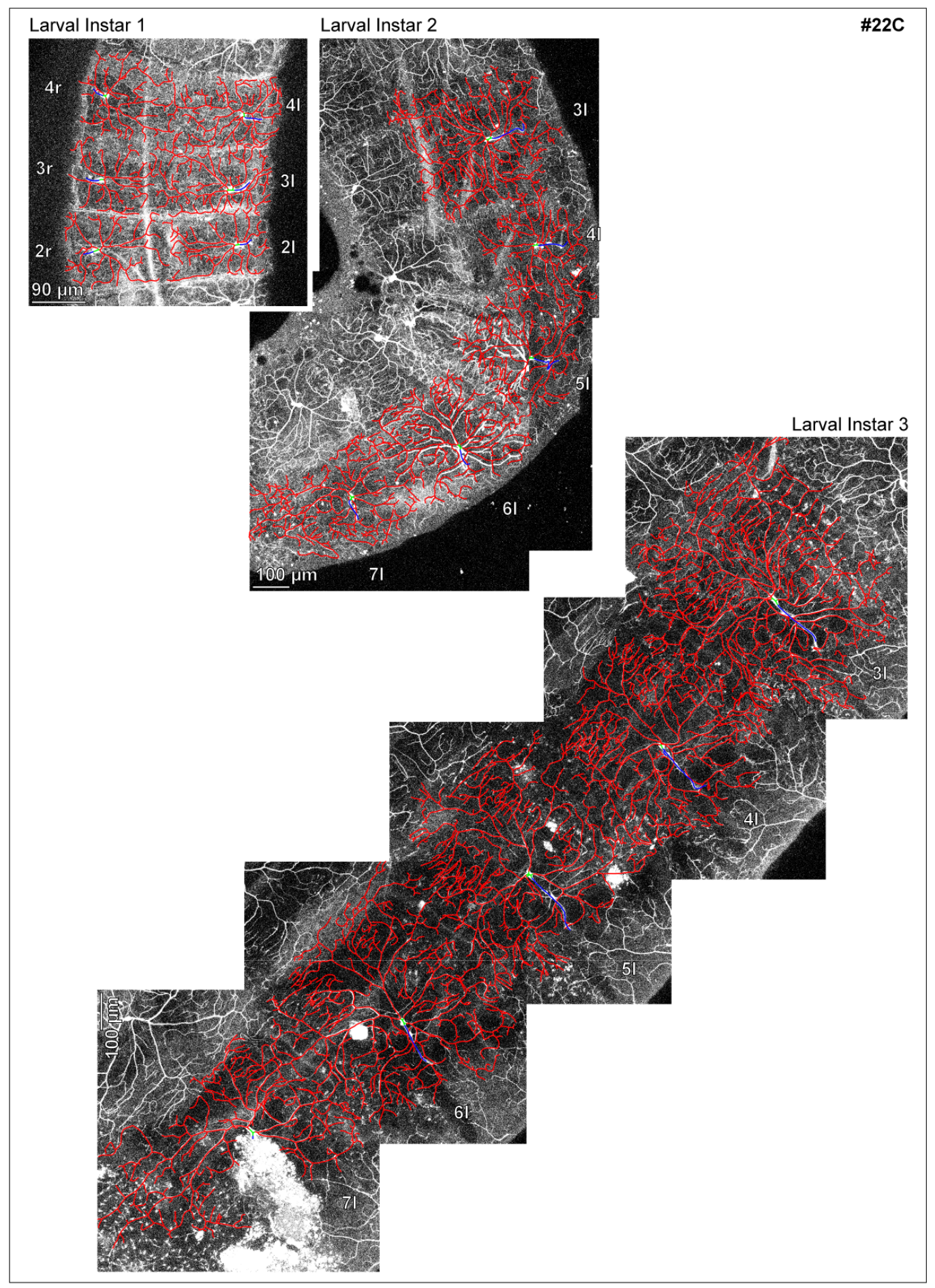

Figure Appendix 6 
bioRxiv preprint doi: https://doi.org/10.1101/2020.07 07.191064; this version posted July 7, 2020. The copyright holder for this preprint (which was not certified by peer review) is the author/funder, who has granted bioRxiv a license to display the preprint in perpetuity. It is made available under aCC-BY-NC-ND 4.0 International license.
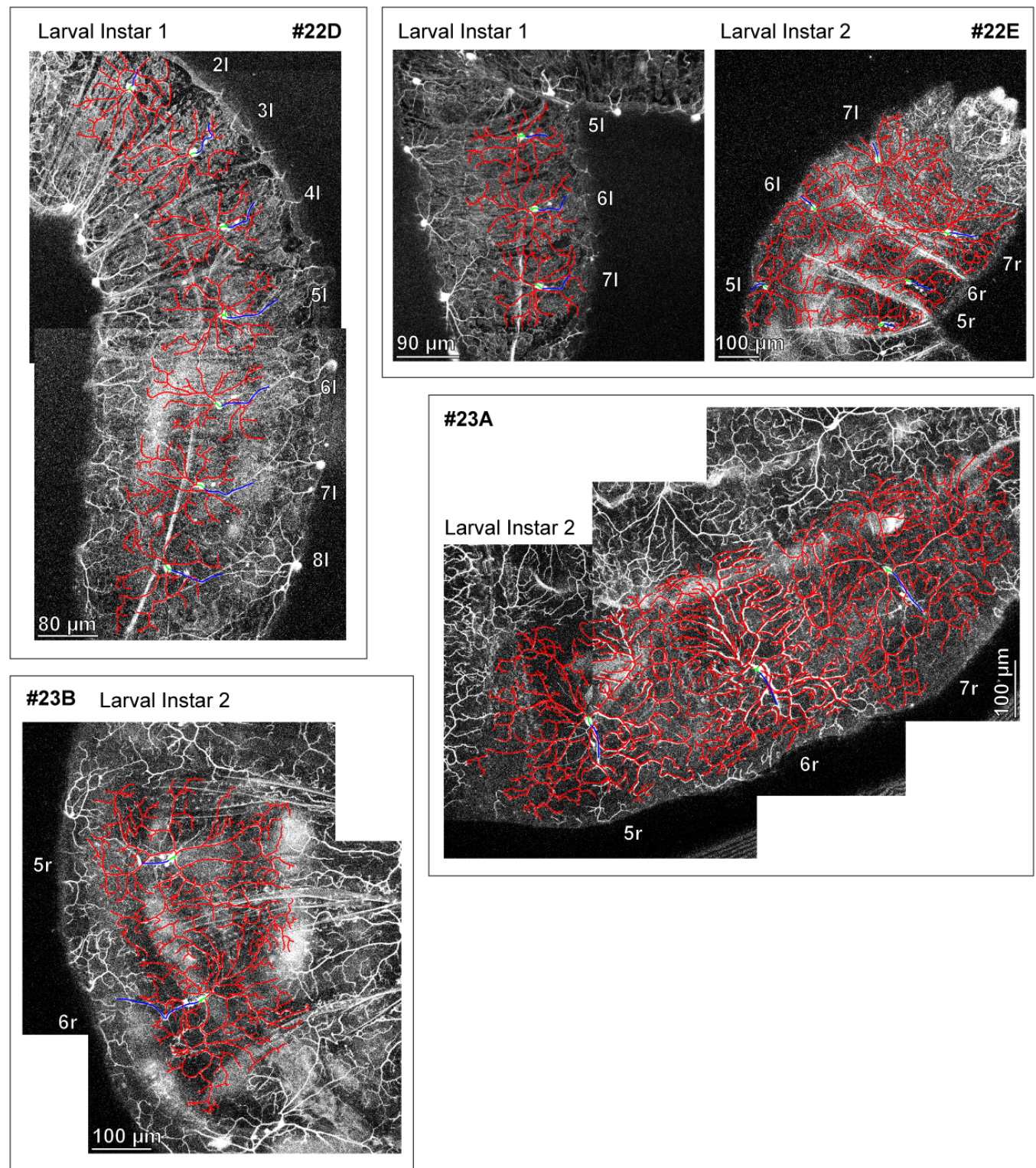

Figure Appendix 7 
bioRxiv preprint doi: https://doi.org/10.1101/2020.07 07.191064: this version posted July 7,2020 . The copyright holder for this preprint (which was not certified by peer review) is the author/funder, who has granted bioRxiv a license to display the preprint in perpetuity. It is made available under aCC-BY-NC-ND 4.0 International license.

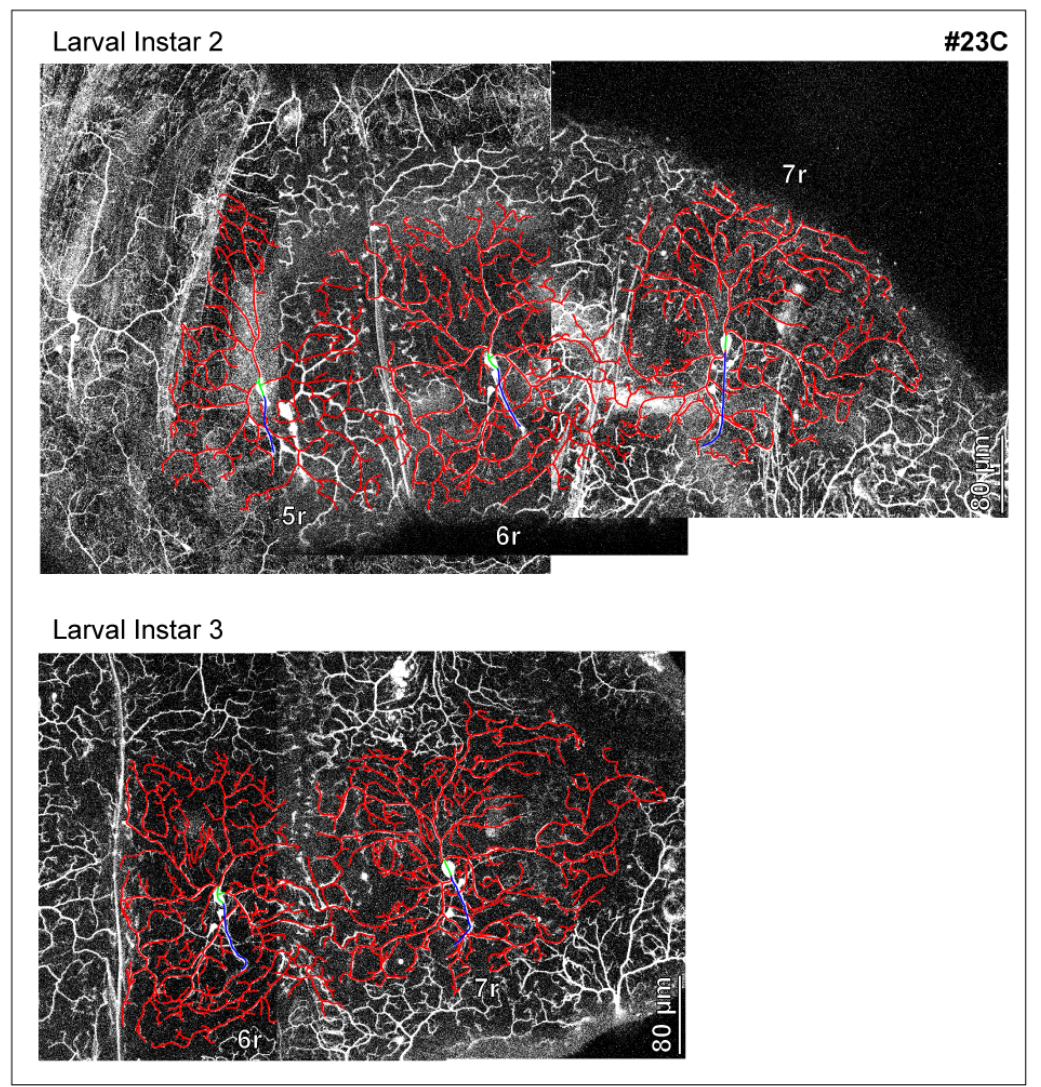

Figure Appendix 8 
bioRxiv preprint doi: https://doi.org/10.1101/2020.07.07.191064; this version posted July 7, 2020. The copyright holder for this preprint (which was not certified by peer review) is the author/funder, who has granted bioRxiv a license to display the preprint in perpetuity. It is made available under aCC-BY-NC-ND 4.0 International license.
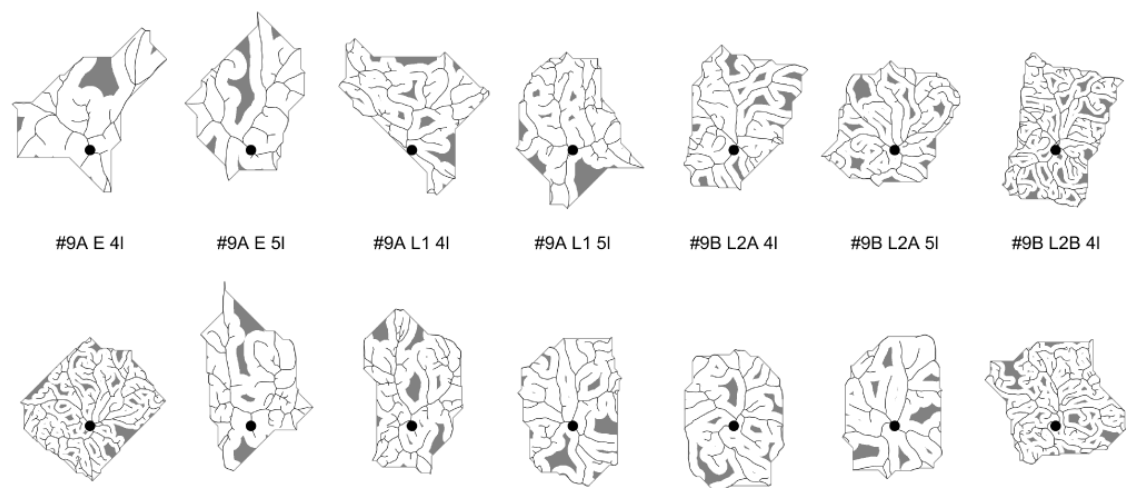

\#9A L1 4I

\#9A L1 51

\#9B L2A 4 I

\#9B L2A 5 ।
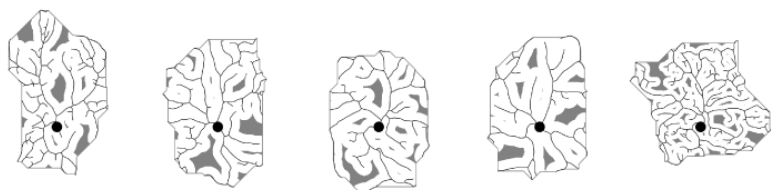

\#9B L2B 5 ।

\#9F E 4r

\#9F E 5 r

\#9F L1 3r

\#9F L1 4r

\#9F L1 5r

\#9F L2 4r
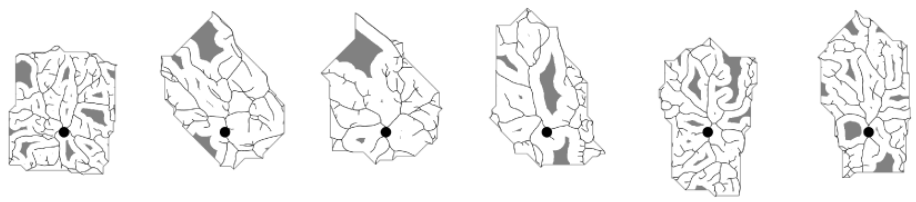

\#9F L2 5 r

\#13A E 3r

\#13A E 4r

\#13A E 5 r

\#13A L1 3r

\#13A L1 4r

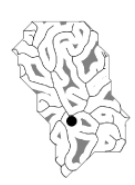

\#13A L1 5r
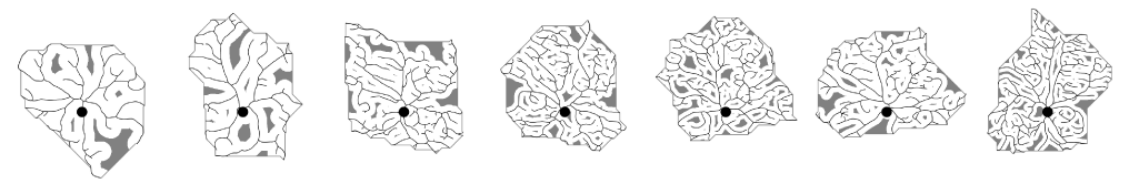

\#13A L1 6r

\#13A L1 7r

\#13A L2 3r

\#13A L2 4r

$\# 13 A$ L2 5 r

\#13A L2 6 r

\#13A L2 31
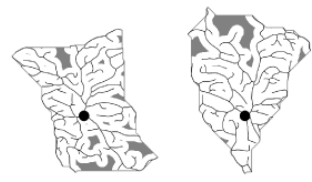

\#13A L2 5 ।

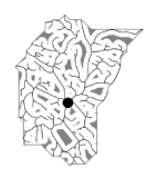

\#13A L2 6 I
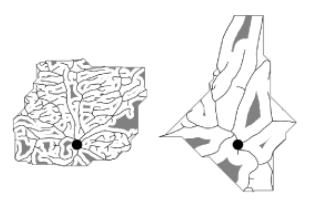

\#13A L3 31

\#20A E 5 r

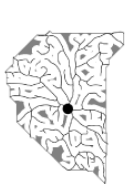

\#13A L2 7 I

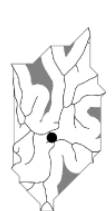

\#20A E 6 r

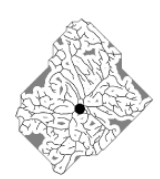

\#13A L3 3r

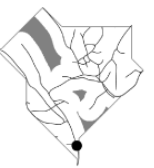

\#20A E 7 r

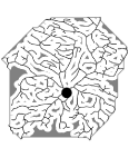

$\# 13$ A L3 4r

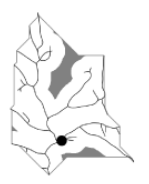

\#20A E 5 I

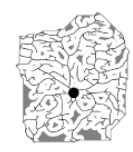

\#13A L3 5r

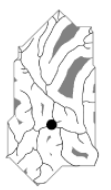

\#20A E 6 I

Figure Appendix 9 
bioRxiv preprint doi: https://doi.org/10.1101/2020.07.07.191064; this version posted July 7, 2020. The copyright holder for this preprint (which was not certified by peer review) is the author/funder, who has granted bioRxiv a license to display the preprint in perpetuity. It is made available under aCC-BY-NC-ND 4.0 International license.
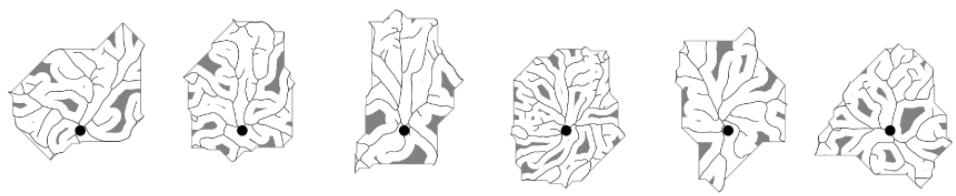

\#9B L2A 4 I

\#9A L1 51

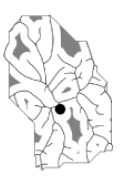

\#9F L1 3r

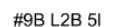

\#9F E 4 r
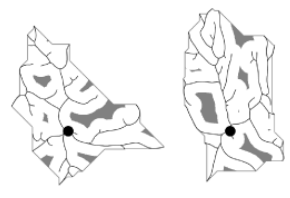

\#9F L2 5r

$\# 13$ A E 3r

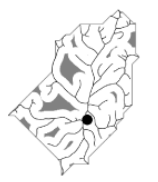

$\# 13$ A L1 6r

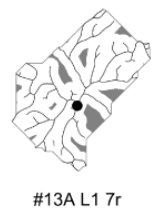

\#13A L1 7r

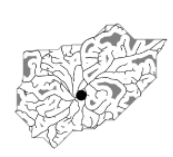

\#13A L2 4 I

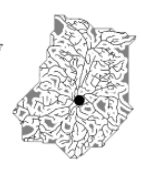

\#13A L2 5 I

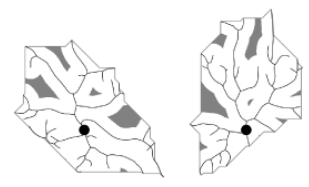

\#13A L3 6r

\#13A L3 31
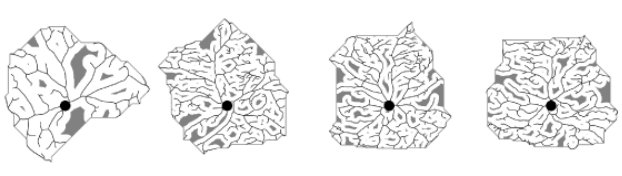

\#13A L2 3r

\#13A L2 4r

\#13A L2 5r

\#13A L2 6r
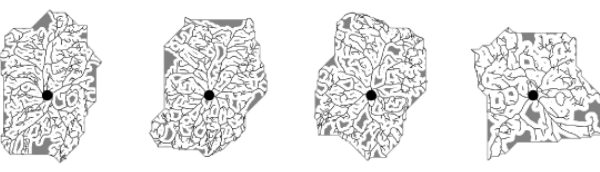

\#13A L2 61

\#13A L2 7 I

\#13A L3 3r

\#13A L3 4r
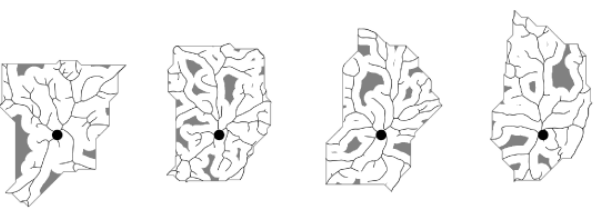

\#20A E 6 r

\#20A E 7 r

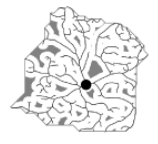

\#13A L2 3 ।

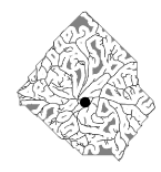

\#13A L3 5 r
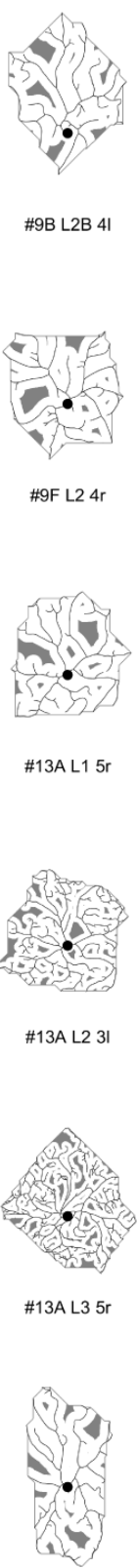

\#9B L2B 4l

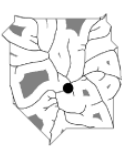

\#9F L2 4r

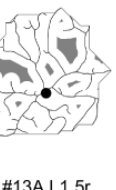

\#20A E 6 I

Figure Appendix 10 
bioRxiv preprint doi: https://doi.org/10.1101/2020.07.07.191064; this version posted July 7, 2020. The copyright holder for this preprint (which was not certified by peer review) is the author/funder, who has granted bioRxiv a license to display the preprint in perpetuity. It is made available under aCC-BY-NC-ND 4.0 International license.

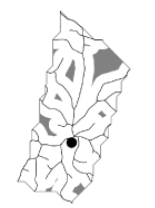

\#9A E 4 I

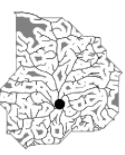

\#9B L2B 51

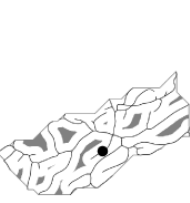

$\# 9$ F L2 5 r

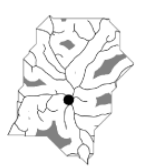

\#13A L1 6 r

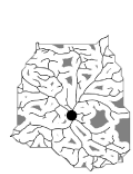

\#13A L2 4।

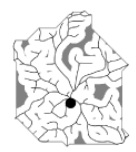

\#13A L3 6 r

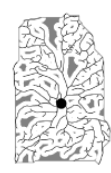

\#9A E 5 I

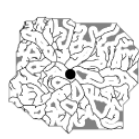

\#9F E 4r

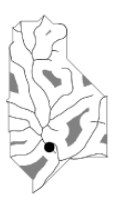

\#13A E 3r

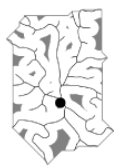

\#13A L1 7r

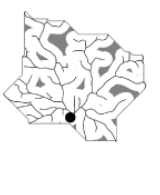

\#13A L2 5 ।

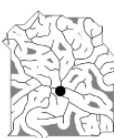

\#13A L3 31
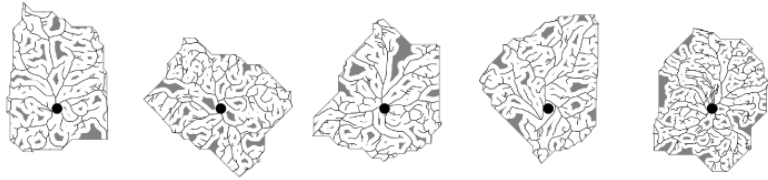

\#9A L1 4 I

\#9A L1 5 I

\#9B L2A 41

\#9B L2A 5 I

\#9B L2B 4I
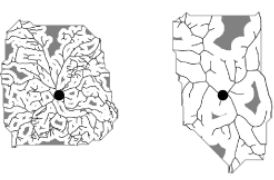

\#9F E 5 r

\#9F L1 3r
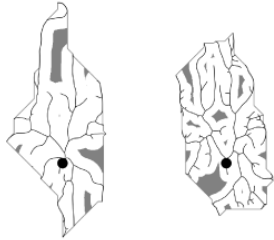

\#9F L1 4r

\#9F L1 5 r

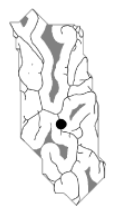

\#9F L2 4r
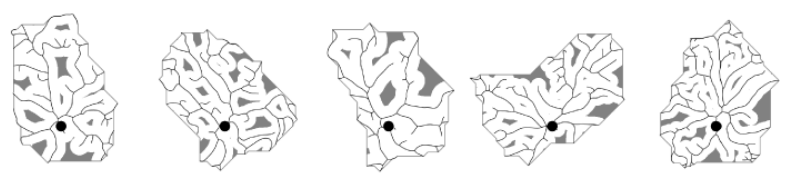

\#13A E 4r

\#13A E 5 r

\#13A L1 3r

\#13A L1 4r

\#13A L1 5r
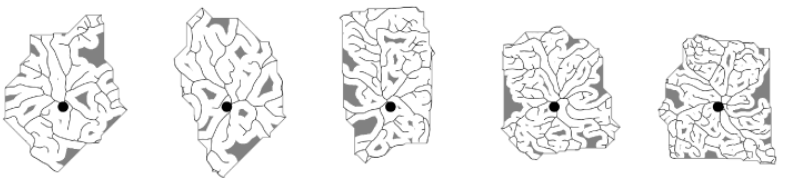

\#13A L2 3r

\#13A L2 4r

\#13A L2 5r

\#13A L2 6 r

\#13A L2 31
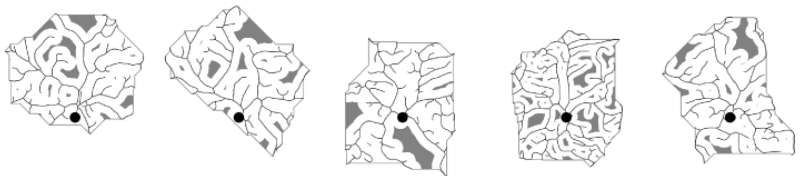

\#13A L2 61

\#13A L2 7 I

\#13A L3 3r

\#13A L3 4r

\#13A L3 5r
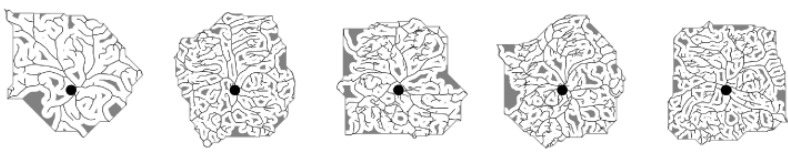

\#20A E 5 r

\#20A E 7r

\#20A E 5

\#20A E 61

Figure Appendix 11 
bioRxiv preprint doi: https://doi.org/10.1101/2020.07.07.191064; this version posted July 7, 2020. The copyright holder for this preprint (which was not certified by peer review) is the author/funder, who has granted bioRxiv a license to display the preprint in perpetuity. It is made available under aCC-BY-NC-ND 4.0 International license.
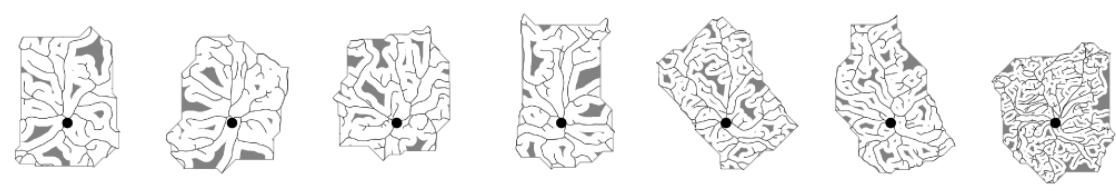

\#9A E 41

$\# 9 A$ E 51

\#9A L1 4 I

\#9A L1 5

\#9B L2A 4 I

\#9B L2A 5 ।

\#9B L2B 4I
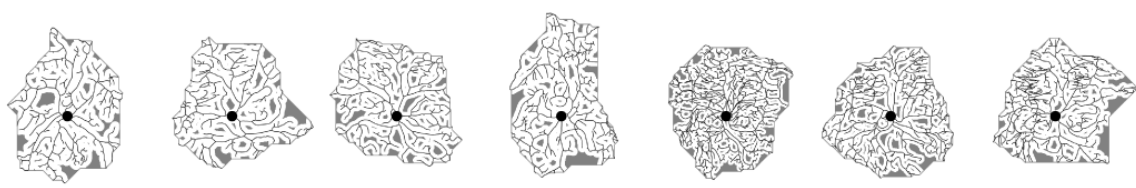

\#9B L2B 5 ।

\#9F E 4 r

\#9F E 5 r

\#9F L1 3r

\#9F L1 4r

\#9F L1 5 r

\#9F L2 4r
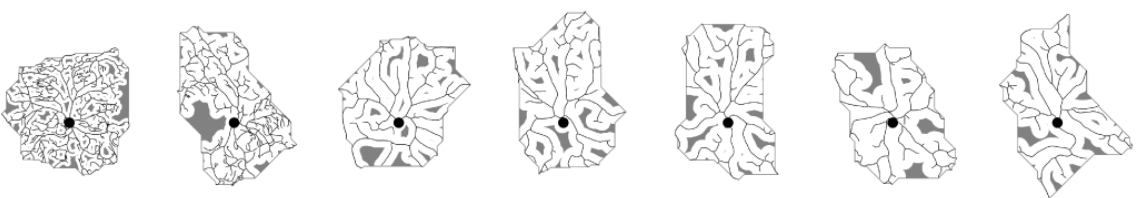

\#9F L2 5r

\#13A E 3r

\#13A E 4 r

\#13A E 5 r

\#13A L1 3r

\#13A L1 4r

\#13A L1 5 r
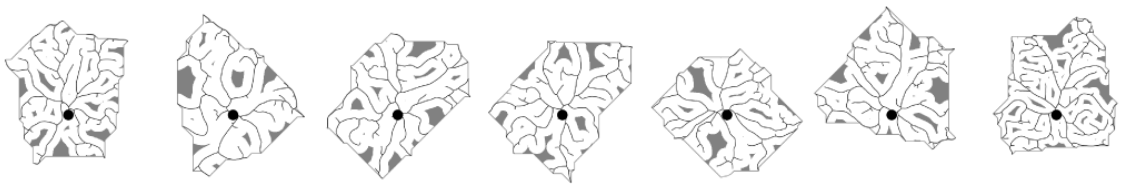

\#13A L1 6 r

\#13A L1 7r

\#13A L2 3r

\#13A L2 4r

\#13A L2 5 r

\#13A L2 6 r

\#13A L2 31
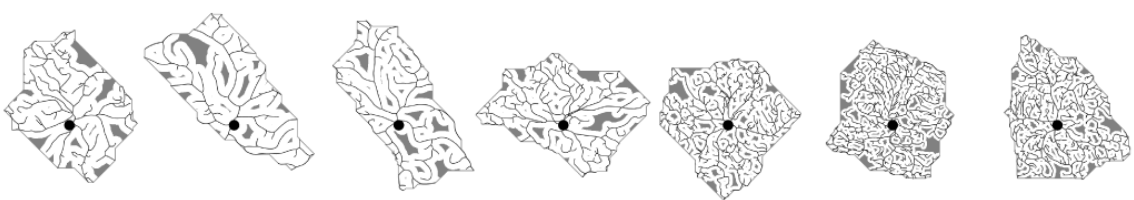

\#13A L2 4I

\#13A L2 5 I

\#13A L2 6 I

\#13A L2 71

\#13A L3 3r

\#13A L3 4r

\#13A L3 5r
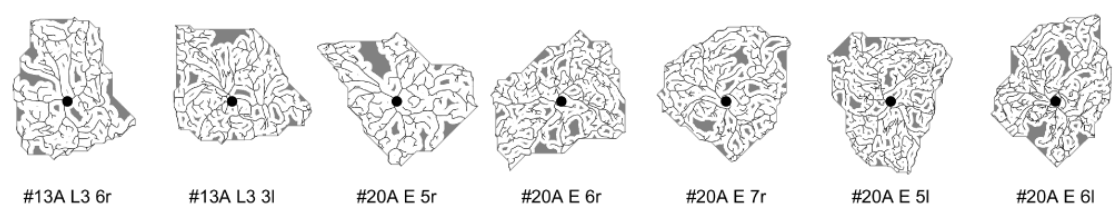

Figure Appendix 12 
bioRxiv preprint doi: https://doi.org/10.1101/2020.07.07.191064; this version posted July 7, 2020. The copyright holder for this preprint (which was not certified by peer review) is the author/funder, who has granted bioRxiv a license to display the preprint in perpetuity. It is made available under aCC-BY-NC-ND 4.0 International license.
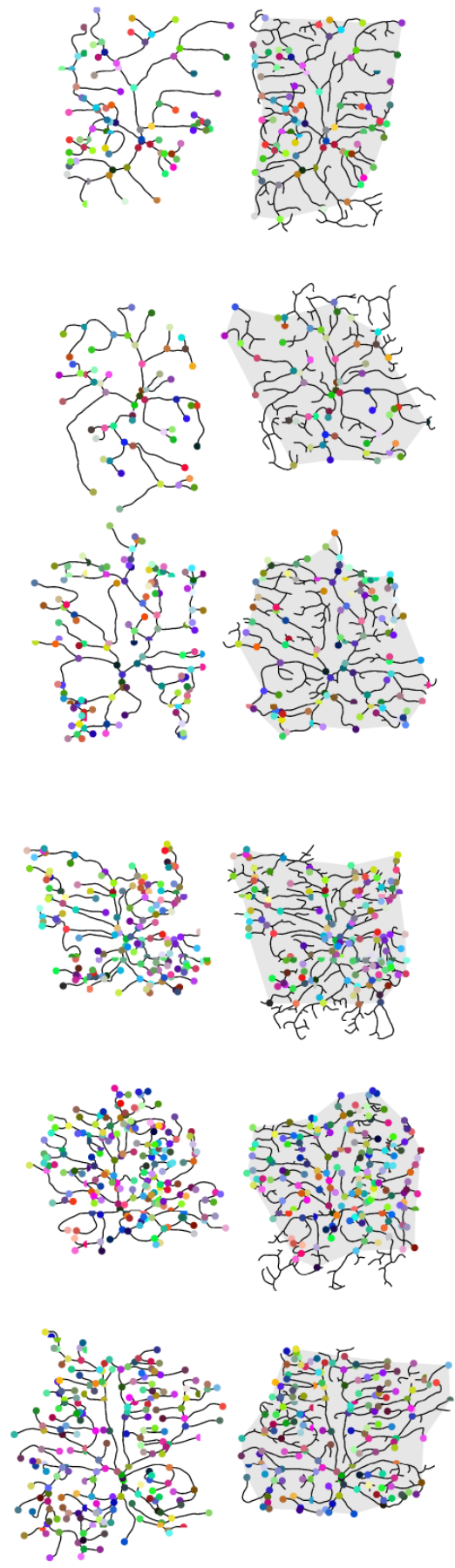
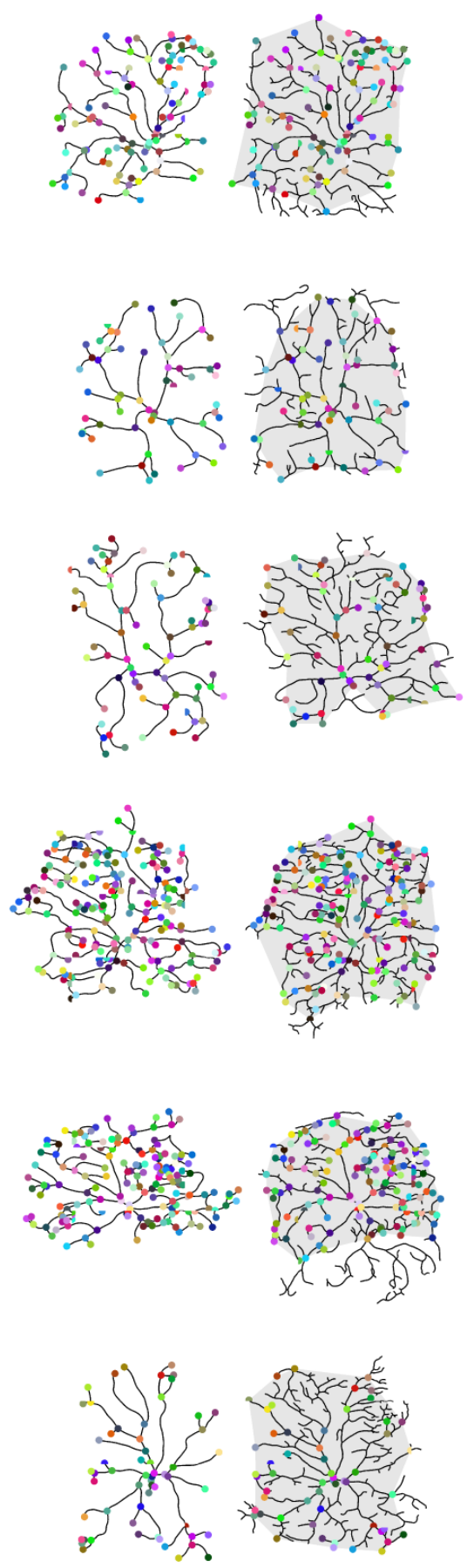

Figure Appendix 13 
bioRxiv preprint doi: https://doi.org/10.1101/2020.07.07.191064; this version posted July 7, 2020. The copyright holder for this preprint (which was not certified by peer review) is the author/funder, who has granted bioRxiv a license to display the preprint in perpetuity. It is made available under aCC-BY-NC-ND 4.0 International license.
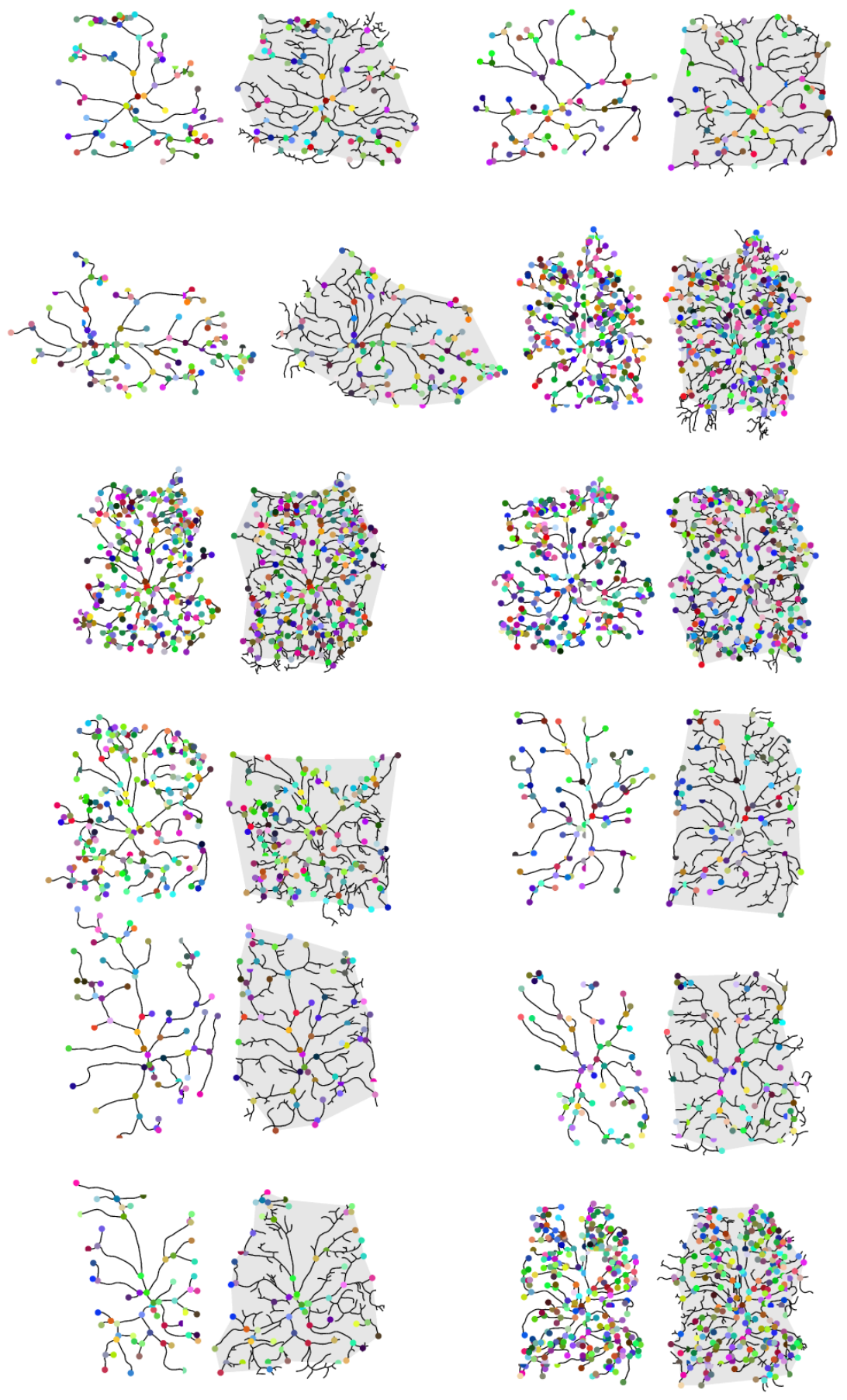

Figure Appendix 14 
bioRxiv preprint doi: https://doi.org/10.1101/2020.07.07.191064; this version posted July 7, 2020. The copyright holder for this preprint (which was not certified by peer review) is the author/funder, who has granted bioRxiv a license to display the preprint in perpetuity. It is made available under aCC-BY-NC-ND 4.0 International license.
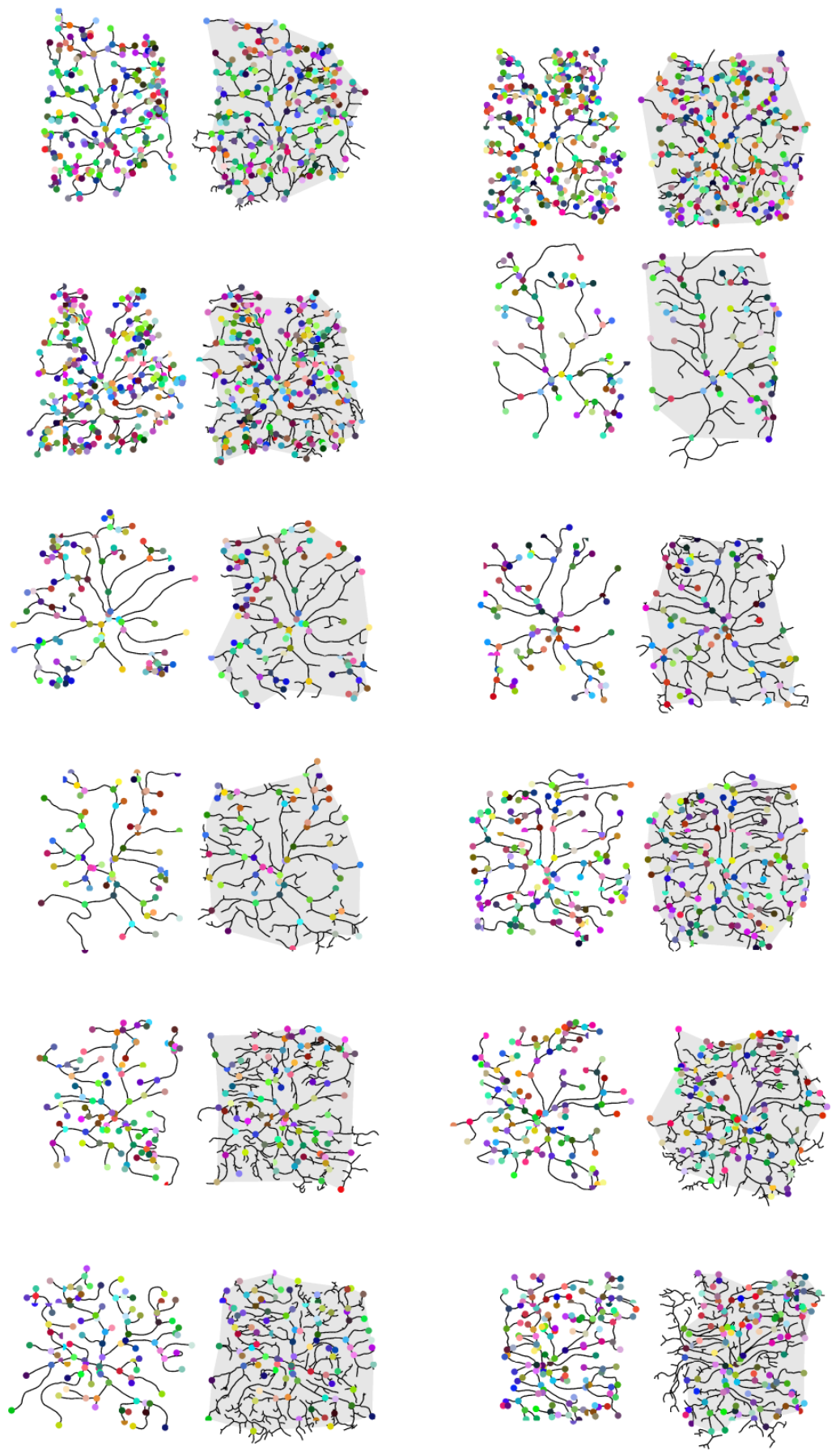

Figure Appendix 15 
bioRxiv preprint doi: https://doi.org/10.1101/2020.07.07.191064; this version posted July 7, 2020. The copyright holder for this preprint (which was not certified by peer review) is the author/funder, who has granted bioRxiv a license to display the preprint in perpetuity. It is made available under aCC-BY-NC-ND 4.0 International license.
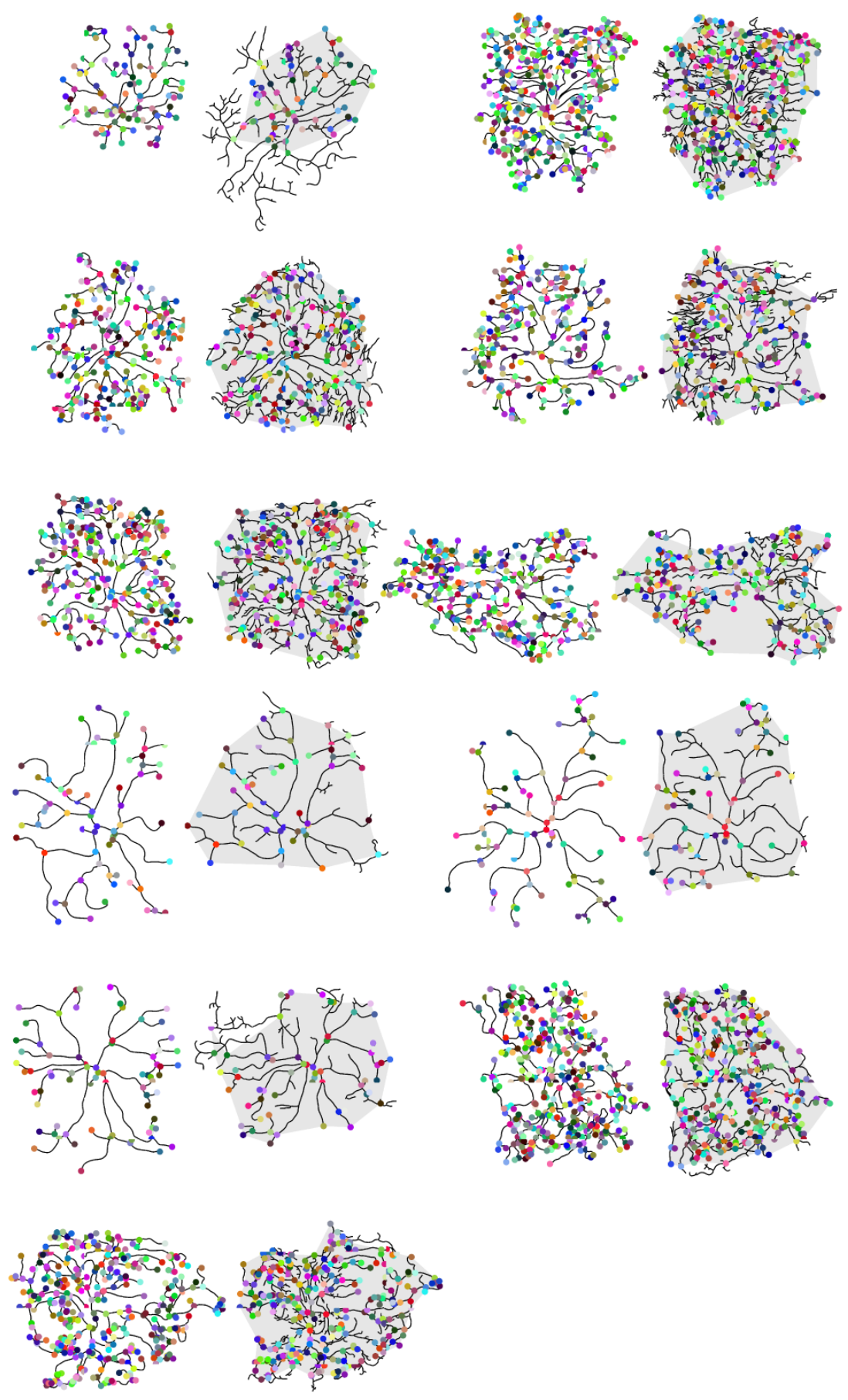

Figure Appendix 16 